\title{
How does downward planetary wave coupling affect polar stratospheric ozone in the Arctic winter stratosphere?
}

\author{
Sandro W. Lubis ${ }^{1, a}$, Vered Silverman ${ }^{2}$, Katja Matthes ${ }^{1,3}$, Nili Harnik ${ }^{2,4}$, Nour-Eddine Omrani ${ }^{5}$, and Sebastian Wahl ${ }^{1}$ \\ ${ }^{1}$ GEOMAR Helmholtz Centre for Ocean Research Kiel, Kiel, Germany \\ ${ }^{2}$ Department of Geophysical, Atmospheric and Planetary Sciences, Tel Aviv University, Tel Aviv, Israel \\ ${ }^{3}$ Christian-Albrechts Universität zu Kiel, Kiel, Germany \\ ${ }^{4}$ Department of Meteorology, University of Stockholm, Stockholm, Sweden \\ ${ }^{5}$ Geophysical Institute, University of Bergen and Bjerknes Centre for Climate Research, Bergen, Norway

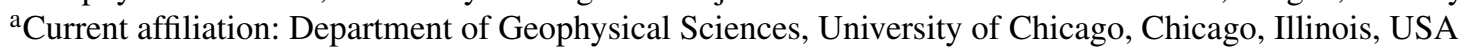

Correspondence to: Sandro W. Lubis (slubis@geomar.de)

Received: 25 June 2016 - Discussion started: 12 August 2016

Revised: 20 December 2016 - Accepted: 26 January 2017 - Published: 15 February 2017

\begin{abstract}
It is well established that variable wintertime planetary wave forcing in the stratosphere controls the variability of Arctic stratospheric ozone through changes in the strength of the polar vortex and the residual circulation. While previous studies focused on the variations in upward wave flux entering the lower stratosphere, here the impact of downward planetary wave reflection on ozone is investigated for the first time. Utilizing the MERRA2 reanalysis and a fully coupled chemistry-climate simulation with the Community Earth System Model (CESM1(WACCM)) of the National Center for Atmospheric Research (NCAR), we find two downward wave reflection effects on ozone: (1) the direct effect in which the residual circulation is weakened during winter, reducing the typical increase of ozone due to upward planetary wave events and (2) the indirect effect in which the modification of polar temperature during winter affects the amount of ozone destruction in spring.

Winter seasons dominated by downward wave reflection events (i.e., reflective winters) are characterized by lower Arctic ozone concentration, while seasons dominated by increased upward wave events (i.e., absorptive winters) are characterized by relatively higher ozone concentration. This behavior is consistent with the cumulative effects of downward and upward planetary wave events on polar stratospheric ozone via the residual circulation and the polar temperature in winter. The results establish a new perspective on dynamical processes controlling stratospheric ozone vari-
\end{abstract}

ability in the Arctic by highlighting the key role of wave reflection.

\section{Introduction}

The dynamical linkage between the stratosphere and troposphere is dominated by planetary waves, which are generated in the troposphere by orographic and/or non-orographic forcing (e.g., Kuroda and Kodera, 1999; Christiansen, 2001; Plumb and Semeniuk, 2003; Polvani and Waugh, 2004). These waves propagate upward into the stratosphere where they either dissipate (often manifested as a sudden stratospheric warming (SSW)) and initiate downward zonal-mean coupling (e.g., Baldwin and Dunkerton, 2001; Limpasuvan et al., 2004), or they are reflected downward toward the troposphere, which results in downward wave coupling (DWC) (e.g., Perlwitz and Harnik, 2003; Shaw et al., 2010; Lubis et al., 2016a). DWC occurs when upward pulses of wave activity decelerate the flow in the upper stratosphere, forming a downward-reflecting surface that redirects waves back to the troposphere (see Harnik and Lindzen, 2001, for theoretical considerations). The occurrence of DWC is tied to the so-called bounded wave geometry of the stratospheric basic state, which is characterized by a well-defined high-latitude meridional waveguide in the lower stratosphere and a vertical reflecting surface in the upper stratosphere (e.g., Shaw et al., 2010; Lubis et al., 2016a). 
The vertical coupling of planetary-scale waves between the stratosphere and troposphere can be directly examined via the meridional eddy heat flux since it is proportional to the vertical group velocity of the planetary waves (e.g., Shaw and Perlwitz, 2013; Lubis et al., 2016a). Using extreme total (climatology plus anomaly) negative wave-1 heat flux values, the life cycle of DWC and its subsequent impact on the circulation in the Northern Hemisphere $(\mathrm{NH})$ have been studied extensively (e.g., Shaw and Perlwitz, 2013, 2014; Dunn-Sigouin and Shaw, 2015; Lubis et al., 2016a). Shaw and Perlwitz (2014) showed that the occurrence of DWC events coincide with a transient reversal of the residual circulation in the stratosphere. This result is consistent with Eliassen-Palm (EP) flux divergence in the stratosphere, induced by transient downward wave propagation during the event (Dunn-Sigouin and Shaw, 2015; Lubis et al., 2016a). Since the variations in the stratospheric EP flux divergence results in changes in the residual circulation (Plumb, 2002), it is therefore expected that DWC may influence the Arctic ozone levels by changing the dynamical transport of ozone to the pole. This hypothesis will be tested in this study.

It is well established that planetary waves play an important role in shaping the ozone hole through their impact on the polar vortex and residual circulation (e.g., Solomon, 1999; Fusco and Salby, 1999; Randel et al., 2002; Lubis et al., 2016b). Randel et al. (2002) showed that variations in planetary wave forcing in the lower stratosphere during winter-spring exhibit a strong correlation with column ozone, via the following mechanism. Increased (decreased) wave dissipation in the stratosphere leads to strengthening (weakening) of residual circulation, which in turn increases (decreases) transport of ozone-rich air to the polar lower stratosphere. Conversely, strong (weak) winter planetary wave forcing causes a warmer (cooler) Arctic lower stratosphere in early spring (Newman et al., 2001), resulting in smaller (larger) chemical ozone losses in spring. Manney et al. (2011) reveal that the unprecedented large Arctic ozone loss in 2011 is highly correlated with extremely cold lowerstratospheric temperatures in early spring. These extremely low temperatures are attributed to the unusually weak midwinter planetary wave forcing in the stratosphere (Hurwitz et al., 2011), as expected from a close relationship between polar spring temperatures and eddy heat flux in mid to late winter (Newman et al., 2001). Both dynamical ozone supply and chemical ozone losses are equally important for the variability of column ozone in the Arctic winter stratosphere (Tegtmeier et al., 2008).

Weaker planetary wave driving in the stratosphere, which affects ozone through both dynamical and chemical processes, could arise from an enhanced number of extreme negative wave-1 heat flux events (i.e., DWC events) or from anomalously low positive heat flux values. Many studies have shown that an increased number of major SSW events that are associated with enhanced upward wave propagation into the stratosphere have led to significant increases in to- tal column ozone and polar temperature in the winter and subsequently less springtime ozone destruction (e.g., Rose and Brasseur, 1985; Randel, 1993). However, the impact of downward wave propagation associated with planetary wave reflection on the ozone in the Arctic winter stratosphere has never been explored. Understanding the impact of DWC on residual circulation and polar temperatures will help to improve our knowledge of the links between stratospheric dynamics and ozone variability.

The goal of this study is to investigate the impact of DWC on polar stratospheric ozone in the NH using both Modern-Era Retrospective analysis for Research and Applications, version 2 (MERRA2, Bosilovich et al., 2015) and the NCAR's Community Earth System Model, version 1.0.2 (CESM1 (WACCM)) model simulation. The new MERRA2 reanalysis improves on and augments the original MERRA reanalysis (Bosilovich et al., 2015). Therefore, it has a better representation of stratospheric ozone in high latitudes compared to the original MERRA reanalysis (see Appendix A1, Figs. A1 and A2). Conversely, the CESM1(WACCM) model is able to capture the main features of DWC in the NH winter (Lubis et al., 2016a); therefore, it can be used to study the link between DWC and polar stratospheric ozone. Here, we focus on two kinds of DWC effects on ozone: (1) the direct effect, which is analyzed over the whole life cycle of the individual DWC event, and (2) indirect effect, which is analyzed through the seasonal impact of DWC on polar temperature.

The paper is structured as follows. Section 2 describes the data and methods. This includes the description of data, model simulation, and methods. In Sect. 3, the direct effects of DWC on the mean residual transport and temperature and ozone concentrations are analyzed, based on the MERRA2 reanalysis product and a 100-year transient simulation from the fully coupled chemistry-climate model CESM1(WACCM). Section 4 discusses the seasonal impacts of DWC events on the Arctic column ozone during seasons that are dominated by enhanced DWC events (reflective winters) and by enhanced upward wave events (absorptive winters). Finally, the results are summarized and discussed in Sect. 5.

\section{Data and methods}

\subsection{MERRA2 ozone}

The new MERRA2 daily ozone product from 1980 to 2013 (Bosilovich et al., 2015) was used to investigate the impact of DWC on ozone. The data were stored on 42 pressure levels from the surface up to $0.1 \mathrm{hPa}$. MERRA2 assimilates ozone from the Solar Backscattered Ultraviolet (SBUV) radiometers from October 1978 to October 2004, and thereafter from the Ozone Monitoring Instrument (OMI) and AURA MLS (Microwave Limb Sounder) instrument (Bosilovich et al., 
2015). These ozone datasets are assimilated with the Goddard Earth Observing System Model, version 5 (GEOS-5) by using odd-oxygen mixing ratio $\left(q \mathrm{O}_{x}\right)$ as its prognostic variable (Bosilovich et al., 2015). This includes an odd-oxygen family transport model that provides the ozone concentration necessary for solar absorption. The vertically integrated ozone tendency is given as (Bosilovich et al., 2015)

$$
\frac{\partial \overline{q \mathrm{O}_{x}}}{\partial t}=\left[-\nabla \cdot\left(\overline{\boldsymbol{v} q \mathrm{O}_{x}}\right)\right]_{\mathrm{DYN}}+\left[\frac{\partial \overline{q \mathrm{O}_{x}}}{\partial t}\right]_{\mathrm{PHY}}+\left[\frac{\partial \overline{q \mathrm{O}_{x}}}{\partial t}\right]_{\mathrm{ANA}} .
$$

The dynamical contribution to the total ozone tendency is the convergence of odd-oxygen mixing ratio products (the first right-hand-side term of Eq. 1). The total physics product (second term) includes the parameterized production and loss terms, and the analysis product (third term) is the corrected ozone tendency from data analysis. The analysis term (i.e., correcting tendency term) is part of the incremental analysis update (IAU) (Bloom et al., 1996), which is used in the GEOS5 model and is an additional forcing to constrain the model to observations. In MERRA2, the total ozone tendency from physics is decomposed into contributions from the chemistry, turbulence, and moist physics. Given a parameterized ozone chemistry in MERRA2, the total ozone tendency from chemistry (CHM) is analyzed together with the correcting tendency term (i.e., CHM + ANA). The contributions of the turbulence and moist physics are negligible in the stratosphere (not shown) and are therefore not considered in this analysis. We confirm that there are no major differences between the MERRA2 and AURA MLS ozone concentrations in the polar lower-to-middle stratosphere (see Appendix A, Figs. A1 and A2).

In addition, daily three-dimensional geopotential height, wind, and temperature fields from MERRA2 with the same period as the ozone (1980 to 2013) were also employed in this study. We note that the nature of downward wave pulses and the associated wave geometry in MERRA2 were found to be in good agreement with the results from the European Centre for Medium-Range Weather Forecasts (ECMWF) ReAnalysis (Lubis et al., 2016a) and the NCEP/NCAR Reanalysis datasets (not shown) and are therefore robust among the various reanalysis products.

\subsection{CESM1(WACCM) simulation}

The model simulation used in this study was performed with the NCAR's CESM version 1.0.2. CESM is a stateof-the-art coupled model system that includes an ocean, land, sea ice, and atmosphere components (Hurrell et al., 2013). The atmospheric component of the CESM used in this study is the Whole Atmosphere Community Climate Model (WACCM) version 4 (Marsh et al., 2013), a fully interactive chemistry-climate model consisting of a finitevolume dynamical core with 66 standard vertical levels (up to $140 \mathrm{~km}$ or $\sim 5.1 \times 10^{-6} \mathrm{hPa}$ ) and a horizontal resolution of $1.9^{\circ}$ latitude $\times 2.5^{\circ}$ longitude. Interactive chemistry is calculated within the 3-D chemical transport Model of Ozone and Related Chemical Tracers, version 3 (MOZART-3; Kinnison et al., 2007). This includes the $\mathrm{O}_{x}, \mathrm{NO}_{x}, \mathrm{HO}_{x}, \mathrm{ClO}_{x}$, and $\mathrm{BrO}_{x}$ chemical families, along with $\mathrm{CH}_{4}$ species within the chemical and physical processes in the troposphere through the lower thermosphere (i.e., fully interactive chemistry and physics).

In this study one 100-year simulation (1955-2054) is free run with fixed surface emissions of greenhouse gases (GHGs) and ozone-depleting substances (ODSs) at 1960s levels, allowing us to study the ozone variability unmasked from any anthropogenic influence. The simulation is run with interactive ocean and sea ice components. To represent a more realistic interaction between the tropics and extratropical dynamics, the quasi-biennial oscillation (QBO) is nudged by relaxing tropical stratospheric zonal-mean winds towards observations following Matthes et al. (2010). The solar cycle is prescribed as spectrally resolved daily variations following Lean et al. (2005). Observed volcanic eruptions of the 20th century are included by prescribing a monthly zonal-mean time series of volcanic aerosol surface area density (SAD), identical to that used in the CCMVal2 REF-B1 simulations (Eyring et al., 2010).

\subsection{Dynamical diagnostics}

The influence of eddies on ozone transport is quantified from the transformed Eulerian mean (TEM) continuity equation for zonal mean tracer concentration (Andrews et al., 1987, Eq. 9.4.13). For linear steady conservative waves, the complete Eulerian mean tracer transport equation can be written in the form

$\bar{\chi}_{t}=-\bar{v}^{*} \bar{\chi}_{y}-\bar{w}^{*} \bar{\chi}_{z}+e^{z / H}(\nabla \cdot \boldsymbol{M})+\bar{S}$.

Equation (2) separates the local change in tracer concentration $\bar{\chi}_{t}$ as a result of transport processes that occur due to advection by the residual circulation $\left(\bar{v}^{*}, \bar{w}^{*}\right)$, the eddy effects $\left(\rho_{0}^{-1} \nabla \cdot \boldsymbol{M}\right)$, and the chemical production minus loss rate $(\bar{S})$ (Andrews et al., 1987). Here, $\boldsymbol{M}$ represents the diffusive effects of the eddies, plus advective effects that are not represented by the residual meridional circulation. The eddy effects are defined as the divergence of the eddy transport vector $(\boldsymbol{M})$, with components defined as in Eq. (9A.3) of Andrews et al. (1987):

$\mathbf{M}=\left(\begin{array}{l}\mathbf{M}^{(y)} \\ \mathbf{M}^{(z)}\end{array}\right)=\left(\begin{array}{c}-e^{-z / H}\left(\overline{v^{\prime} \chi^{\prime}}-{\overline{v^{\prime} \theta^{\prime}}}_{\chi_{z}} / \bar{\theta}_{z}\right) \\ -e^{-z / H}\left(\overline{w^{\prime} \chi^{\prime}}+{\overline{v^{\prime} \theta^{\prime}}}_{\chi_{y}} / \bar{\theta}_{z}\right)\end{array}\right)$.

The overbars indicate zonal means, primes are deviations from it, and subscripts denote partial derivatives. The $\bar{v}^{*}$ and $\bar{w}^{*}$ in Eq. (2) denote the TEM residual meridional and vertical winds defined as $\bar{v}^{*}=\bar{v}-\rho_{0}^{-1}\left(\rho_{0} \overline{v^{\prime} \theta^{\prime}} / \bar{\theta}_{z}\right)_{z}$ and $\bar{w}^{*}=\bar{w}+(a \cos \phi)^{-1}\left(\cos \phi \overline{v^{\prime} \theta^{\prime}} / \bar{\theta}_{z}\right)_{\phi}$, respectively. The potential temperature and scale height are represented by $\theta$ 
and $H$, respectively. The Coriolis parameter and Earth's radius are denoted by $f$ and $a$. We note that the sum of the first three right-hand-side terms of Eq. (2) is equal to the total ozone tendency from dynamics in Eq. (1), while the last term of Eq. (2) is equal to the total ozone tendency due to chemistry and analysis in Eq. (1). In addition, the residual mean circulation calculated from the residual mass stream function $\left(\Psi_{m}\right)$ and the wave geometry diagnostic are also used in this study (see Appendix B, Eqs. B1-B4).

\section{Identification of DWC event}

We use a similar definition of a DWC event as in Lubis et al. (2016a) and Dunn-Sigouin and Shaw (2015), which is based on daily total (climatology plus anomaly) negative wave-1 meridional heat flux $\left(\overline{v^{\prime} T^{\prime}} k=1\right)$ at $50 \mathrm{hPa}$ averaged between 60 and $90^{\circ} \mathrm{N}$, below the fifth percentile of the daily $\overline{v^{\prime} T^{\prime}}{ }_{k=1}$ distribution. We focus our analysis on January, February, and March (JFM), which is the period of maximum planetary wave coupling between the troposphere and stratosphere in the NH (Shaw et al., 2010; Lubis et al., 2016a). For time-lagged composites, the central date is the day on which ${\overline{v^{\prime} T^{\prime}}}_{k=1}$ has a minimum. Finally, the central dates of each event must be separated by at least 15 days. The time separation threshold is motivated by the timescale of planetary wave coupling between the stratosphere and troposphere (Perlwitz and Harnik, 2003). Events defined using the $\overline{v^{\prime} T^{\prime}}{ }_{k=1}$ at 30 and $10 \mathrm{hPa}$ exhibit similar qualitative behavior as those defined at $50 \mathrm{hPa}$.

Applying our identification algorithm leads to a total number of 19 potential DWC events in MERRA2 reanalysis (see Table 1) and 58 in CESM1(WACCM) (see Table S1 in the Supplement). The frequency of DWC events in MERRA and CESM1(WACCM) is similar, about six events per decade. We also note that the number of events found here and the evolution of the downward and upward wave pulses are in good agreement with the results of Dunn-Sigouin and Shaw (2015) (see later in Fig. 1). The minimum value of the total 5-day smoothed ozone tendency from 60 to $90^{\circ} \mathrm{N}$ during the dates of the DWC events is shown in Table 1. It can be seen that DWC events are instantaneously linked to a transient reduction in ozone in the Arctic mid-stratosphere (see Table 1 for MERRA2 and Table S1 for CESM1(WACCM)). All the statistical significance for the composites is reported at the $95 \%$ level, based on a 1000-trial Monte Carlo test (see Appendix $\mathrm{C}$ ). The composites are done both for the total fields and the anomalies, which are defined as deviation from the daily climatological seasonal cycle.
Table 1. Central dates of potential DWC events at $50 \mathrm{hPa}$ and the minimum total 5-day smoothed wave-1 heat flux $\left(\mathrm{K} \mathrm{m} \mathrm{s}^{-1}\right)$ and ozone tendency $\left(\times 10^{-2} \mathrm{ppmv}^{-1 a y}{ }^{-1}\right)$ from 60 to $90^{\circ} \mathrm{N}$ during the event in MERRA2.

\begin{tabular}{|c|c|c|c|}
\hline Dates & $\min _{60-90^{\circ}}{\overline{v^{\prime} T^{\prime}}}_{k=1}$ & $\begin{array}{r}\min _{60-90^{\circ} N} \\
\mathrm{dO}_{3} / \mathrm{d} t \\
(\mathrm{MERRA} 2)\end{array}$ & $\begin{array}{r}\min _{60-90^{\circ} N} \\
\mathrm{dO}_{3} / \mathrm{d} t \\
(\mathrm{MLS})\end{array}$ \\
\hline 17 Feb 1981 & -37.84 & -20.11 & - \\
\hline 14 Mar 1982 & -68.71 & -12.62 & - \\
\hline 25 Jan 1986 & -44.07 & -14.86 & - \\
\hline 26 Feb 1989 & -120.38 & -29.83 & - \\
\hline 14 Feb 1990 & -54.73 & -14.65 & - \\
\hline 23 Mar 1990 & -53.08 & -18.74 & - \\
\hline 1 Feb 1991 & -27.35 & -13.61 & - \\
\hline 23 Jan 1992 & -50.77 & -10.15 & - \\
\hline 22 Mar 1993 & -52.17 & -13.63 & - \\
\hline 11 Mar 1994 & -40.07 & -8.21 & - \\
\hline 28 Mar 1995 & -72.76 & -22.31 & - \\
\hline 13 Jan 1996 & -51.95 & -8.62 & - \\
\hline 14 Mar 1996 & -151.45 & -47.11 & - \\
\hline 23 Mar 2000 & -31.86 & -18.49 & - \\
\hline 8 Mar 2002 & -50.09 & -12.24 & - \\
\hline 10 Jan 2007 & -39.52 & -7.51 & -6.90 \\
\hline 21 Mar 2007 & -73.02 & -21.5 & -27.41 \\
\hline 28 Jan 2008 & -65.16 & -4.33 & -3.58 \\
\hline 28 Feb 2008 & -79.17 & -15.16 & -13.24 \\
\hline
\end{tabular}

\section{Direct effect of the DWC on polar stratospheric ozone}

In the following sections we examine the effect of DWC events on polar stratospheric ozone in the observations and then in the model.

\subsection{Observed effect of DWC on ozone}

To examine the effects of DWC events on polar stratospheric ozone we first examine the connection between DWC, residual circulation, and Arctic temperatures during the composite life cycle of DWC in MERRA2 reanalysis. Figure 1a-d show the composite life cycle of downward planetary wave events as a function of pressure and time from -20 to +20 days for (a) wave-1 heat flux anomaly, (b) wave-1 EP flux divergence anomaly, (c) residual circulation anomaly, and (d) total potential temperature tendency. There is a positive heat flux anomaly that migrates from the troposphere to the upper stratosphere from days -10 to -4 (Fig. 1a). This heat flux evolution coincides with large changes in anomalous wave-1 EP flux convergence in the high latitudes (Fig. 1b), suggesting that the upward propagating waves dissipate in the upper stratosphere prior to a DWC event. The associated EP flux convergence forces an anomalous positive (i.e., poleward) residual circulation and thus leads to positive potential temperature tendency in the Arctic stratosphere (Fig. 1c 

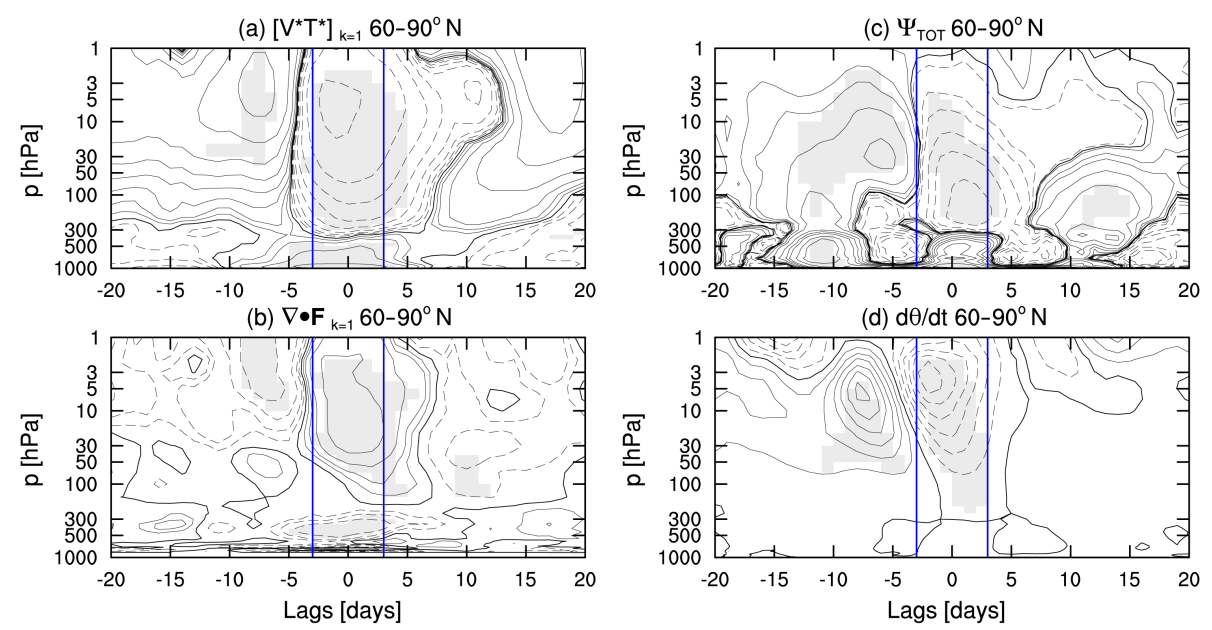

Figure 1. Evolution of DWC events as a function of time from days -20 to +20 and pressure from MERRA2: (a) wave-1 meridional heat flux anomaly (black contours), (b) wave-1 EP flux divergence anomaly, (c) residual mass-stream function anomaly, and (d) potential temperature tendency averaged from 60 to $90^{\circ} \mathrm{N}$. The contour intervals are $\pm[1,2,4,8,16,32, \ldots] \mathrm{Km}^{-1}$ for (a), $\pm[0.5,1,2,4,8,16, \ldots] \mathrm{m} \mathrm{s}^{-1}$ day $^{-1}$ for (b), $\pm 1 \times 10^{9}[0.5,1,2,4,8,16,32,64, \ldots] \mathrm{kg} \mathrm{s}^{-1}$ for (c), and $\pm 0.5 \mathrm{~K} \mathrm{day}^{-1}$ for (d). The gray shading indicates statistical significance at the $95 \%$ level using a 1000-trial Monte Carlo test. The periods of the maximum DWC event (days -3 to +3 ) are bounded by two vertical blue lines.

and d). This positive potential temperature tendency is associated with air being advected downward over the pole, producing anomalous adiabatic warming. The changes in the residual circulation and the temperature tendency are consistent with anomalous EP flux convergence in the stratosphere due to upward propagation of planetary-scale waves prior to a DWC event.

From days -3 to +3 , the stratospheric heat flux anomaly subsequently changes sign and reaches its minimum value (Fig. 1a). The high-latitude negative heat flux anomalies coincide with EP flux divergence anomalies in the stratosphere (Fig. 1b), suggesting that the upward propagating waves are reflected downward toward the troposphere, resulting in EP flux divergences in the stratosphere. The high-latitude wave1 EP flux divergence are dominated by the vertical component (not shown). In addition, the EP flux divergence anomalies resulting from transient evolution of the downward wave activity lead to anomalous negative (i.e., equatorward) residual circulation and the associated negative potential temperature tendency in the polar stratosphere (Fig. 1c and d). The negative residual circulation anomaly suggests a deceleration of poleward transport of air mass, resulting in negative potential temperature tendency over this region. The negative residual circulation and temperature tendency are consistent with anomalous EP flux divergence in the stratosphere induced by transient downward wave activity from the stratosphere to the troposphere during the mature stage of the DWC event. From day +4 onwards, the associated anomalies become statistically insignificant.

Next, we analyze the implication of transient changes in residual circulation induced by DWC on polar stratospheric ozone in MERRA2. Figure 2 shows the corresponding tran- sient evolution of the zonal-mean ozone tendencies averaged between 60 to $90^{\circ} \mathrm{N}$. During downward wave events, the high-latitude total ozone tendency exhibits similar behavior as the heat flux pulse and the residual circulation. In particular, the event begins with a positive high-latitude stratospheric ozone tendency in the stratosphere from days -15 to -5 (Fig. 2a). This positive stratospheric ozone tendency subsequently changes sign and reaches its minimum value at $10 \mathrm{hPa}$, around day 0 (Fig. 2a). The evolution of the total ozone tendency is consistent with the evolution of highlatitude residual circulation anomalies (Fig. 1a). In particular, the positive (poleward) residual circulation anomaly in the stratosphere from days -15 to -5 lead to more ozone transport to the polar vortex, and the subsequent negative (equatorward) residual circulation anomalies between days -4 to +5 leads to more ozone transport out of the polar vortex.

To investigate the source of the transient changes in polar stratospheric ozone during DWC events, we decompose the total ozone tendency (Fig. 2a) into contributions of dynamics and chemistry-plus-analysis terms. It is shown that the evolution of total ozone tendency in the mid-lower and midupper stratosphere (between 100 and $1 \mathrm{hPa}$ ) is dominated by the dynamical term (Fig. 2b). The ozone tendency due to dynamics in the mid-lower stratosphere $(100$ and $10 \mathrm{hPa})$ is mainly attributed to the ozone transport via vertical (advection) residual circulation (Fig. 2d), while the tendency in the mid-upper stratosphere (above $5 \mathrm{hPa}$ ) is mainly attributed to effects of eddy transport (Fig. 2f). Therefore, the dominance of the dynamical term on the total ozone tendency in the midlower stratosphere during the composite life cycle is consistent with the transient changes in residual mean transport (Fig. 1c). Conversely, the contribution of the chemistry to 

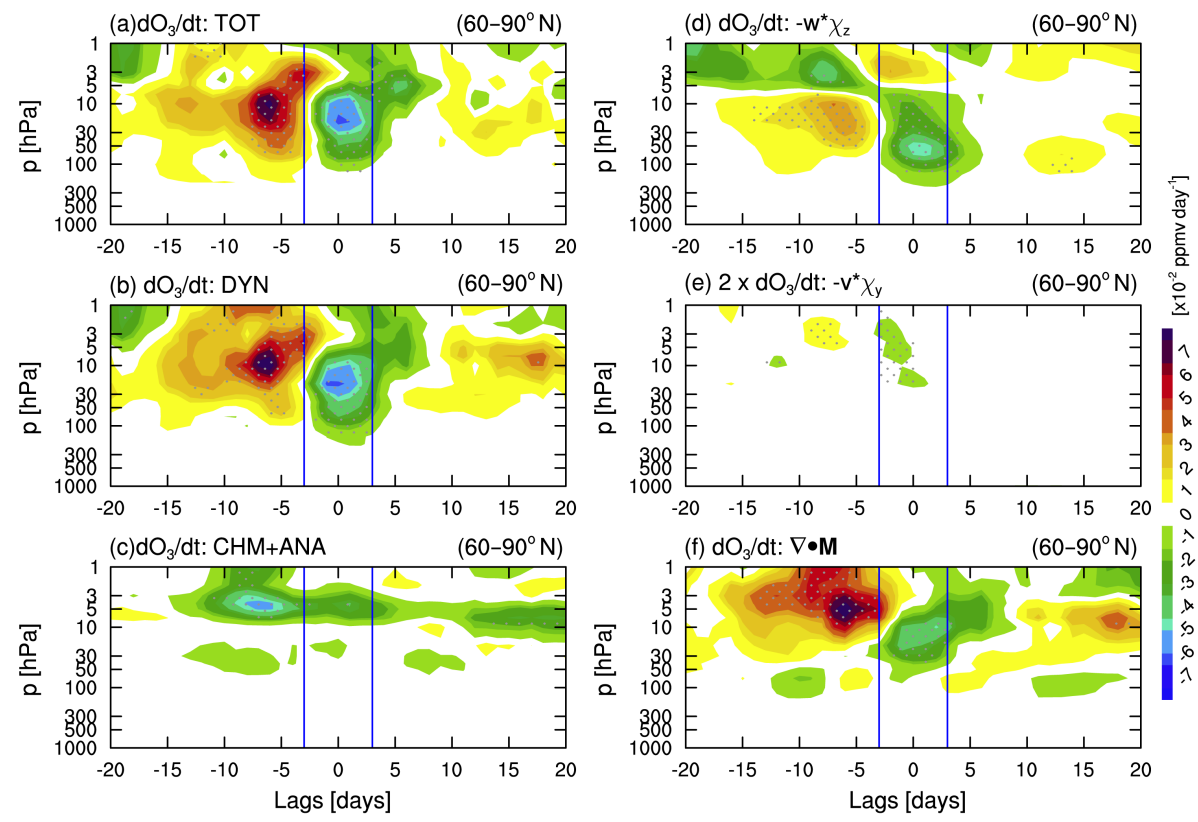

Figure 2. Evolution of the ozone tendencies for the composite of DWC event as a function of time and pressure, averaged from 60 to $90^{\circ} \mathrm{N}$ from MERRA2: (a) total ozone tendency, (b) ozone tendency anomaly due to dynamics and (c) due to parameterized chemistry. Tendency due to dynamics is decomposed into (d) vertical advection, (e) meridional advection, and (f) eddy transport effects based on Eq. (1). The periods of the maximum DWC event (days -3 to +3 ) are bounded by two vertical blue lines. Stippling indicates statistical significance at the $95 \%$ level using a 1000-trial Monte Carlo test.

the total ozone tendency (Fig. 2c) is significant above $10 \mathrm{hPa}$ prior to the mature stage of DWC event (from days -10 to -5 , Fig. $2 \mathrm{c}$ ) and peaks around day -7 . The negative ozone tendency due to chemistry in the upper stratosphere prior to DWC is likely associated with more chemical ozone loss due to increased temperature prior to a DWC event (Fig. 1d). This is consistent with the ozone sink reaction in the upper stratosphere, which is strongly dependent on temperature, where the increase (decrease) in temperature leads to more (less) ozone destruction (Brasseur and Solomon, 2005). However, the magnitude is relatively weak compared to that caused by dynamics. These results suggest that transient changes in the polar mid-lower stratospheric ozone during the DWC life cycle are primarily due to changes in dynamical ozone transport.

The same conclusion can be drawn by assessing the instantaneous correlation between the two extreme stratospheric wave-1 heat flux events. Figure $3 \mathrm{a}$ shows a twodimensional histogram of total ozone tendency versus residual vertical wind anomaly $\left(w^{*}\right)$ averaged over $60-90^{\circ} \mathrm{N}$ at $50 \mathrm{hPa}$ in MERRA2. The black contour lines indicate the distribution of all daily JFM samples from 1980 to 2013 (90 days $\mathrm{yr}^{-1} \times 34 \mathrm{yr}=3060$ days). The red and blue dots indicate the days with positive and negative extremes in total wave-1 heat flux, respectively (the top and bottom $5 \%$ ). Negative extremes are associated with DWC events. The overall shape of the distribution suggests a strong negative correlation between polar-cap-averaged ozone tendency and $w^{*}$.
This is consistent with a direct calculation of time series correlation, which is statistically significant $(R=-0.81)$. In addition, the days with positive and negative extremes (red and blue dots, respectively) are systematically skewed compared to the background distribution, suggesting that enhanced extreme negative heat flux (i.e., stronger DWC event) corresponds to a weaker residual circulation and a higher negative ozone tendency, and vice versa for positive extremes. In addition, Fig. 3b shows a similar diagnostic, but for the dynamical ozone tendency vs. $w^{*}$. Again, the overall two-dimensional distribution suggests a strong negative correlation between dynamical ozone tendency and the vertical component of the residual circulation, with a temporal correlation coefficient of -0.82 . This reflects the fact that the dynamical ozone tendency is strongly correlated with changes in residual circulation. In addition, we found a weak instantaneous relationship between chemical ozone tendency and temperature tendency in the upper stratosphere $(R=-0.19$, Fig. 3c), suggesting that transient changes of ozone due to chemistry are less robust compared to the dynamical term. We note that although the analyses in Fig. 3 are based on the $5 \%$ negative extreme events, the described relationships do not depend on the fraction of extreme events considered (not shown), and thus these results are representative of the general behavior. The same conclusions are also obtained and are even more robust when we used total column ozone tendency (TCO) instead of an ozone-mixing ratio at $50 \mathrm{hPa}$ (not shown). The results suggest that the instantaneous link between ozone and extreme 

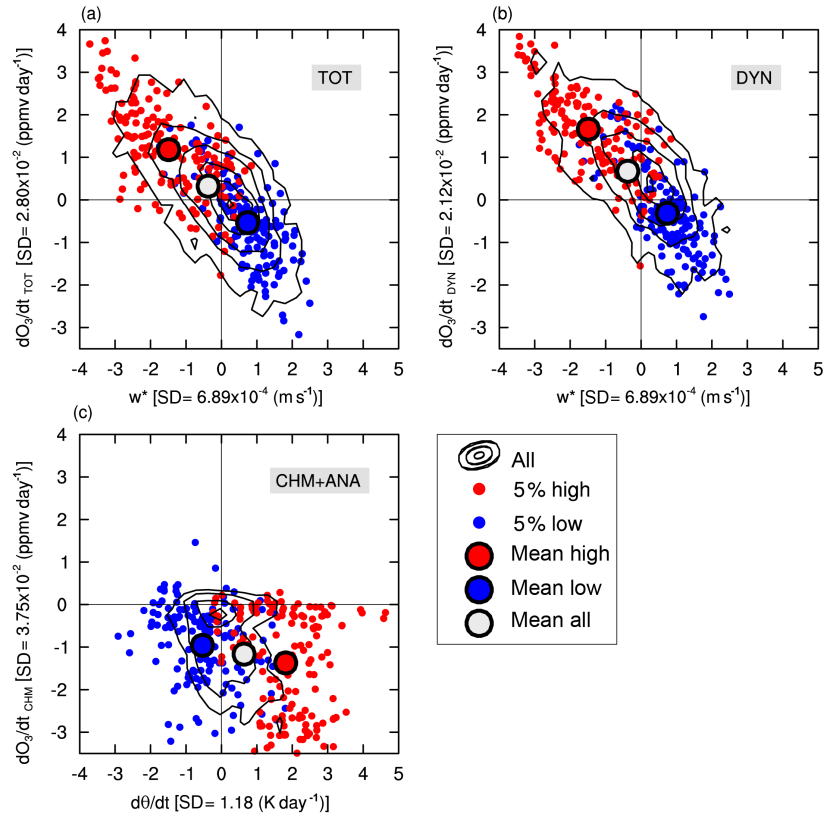

Figure 3. Two-dimensional joint probability density distribution of (a) residual vertical wind velocity versus total ozone tendency, (b) residual vertical wind velocity versus ozone tendency due to dynamics, and (c) potential temperature tendency versus ozone tendency due to parameterized chemistry, averaged over 60 to $90^{\circ} \mathrm{N}$ at $50 \mathrm{hPa}$ (for a, b) and at $5 \mathrm{hPa}$ (for c), in JFM from MERRA2. The axes are normalized to standard deviations in each quantity. Black contours show the probability distribution of all JFM days during 1980-2013 (contours shown are 1, 2, 3, 4, 5, . \% of total). Red and blue dots show days with $5 \%$ extreme maximum and minimum total wave- 1 meridional heat flux. Larger circles indicate the mean of the distribution of all data (gray), high extremes (red), and low extremes (blue).

wave-1 heat flux events is more dominated by the dynamical process, consistent with the results from Fig. 2 where the transient changes of ozone during the life cycle of DWC are mainly due to changes in ozone transport.

Our results so far indicate that the life cycle of DWC involves a transient reversal of poleward to equatorward residual circulation anomaly and subsequent changes in potential temperature tendency and ozone from being positive to negative values. Therefore, it is worth checking whether the effects on residual circulation, temperature tendency, and ozone over the life cycle of the wave could integrate to zero, indicating that the impacts would be reversible. To this end, we first calculated the time integration of residual circulation anomaly and temperature tendency averaged over the levels where their effects are significant (i.e., between 100 and $1 \mathrm{hPa}$ ) (Fig. 4a and b). The results show that both timeintegrated residual circulation and temperature tendency over the composite of DWC life cycle are nearly zero, indicating that the impacts are reversible. The reversibility implies that the effect of DWC on the residual circulation and tem- (a) $\Psi_{\text {TOT }}\left[100-1 \mathrm{hPa}, 60-90^{\circ} \mathrm{N}\right]$

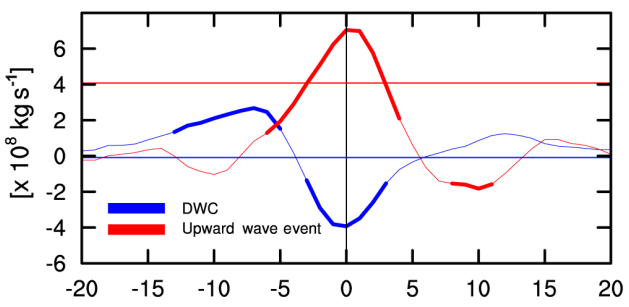

(b) $\mathrm{d} \theta / \mathrm{dt}\left[100-1 \mathrm{hPa}, 60-90^{\circ} \mathrm{N}\right]$

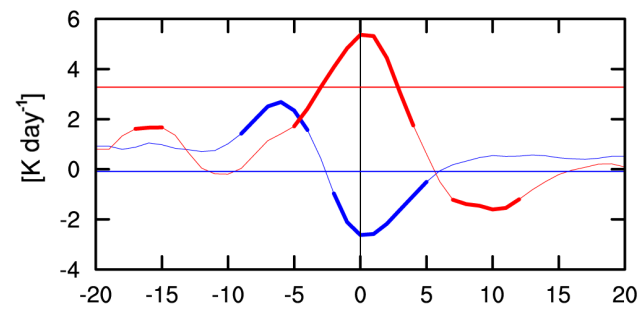

(c) dTCO/dt (solid) \& $\mathrm{dO}_{3} / \mathrm{dt}$ at $50 \mathrm{hPa}$ (dashed)

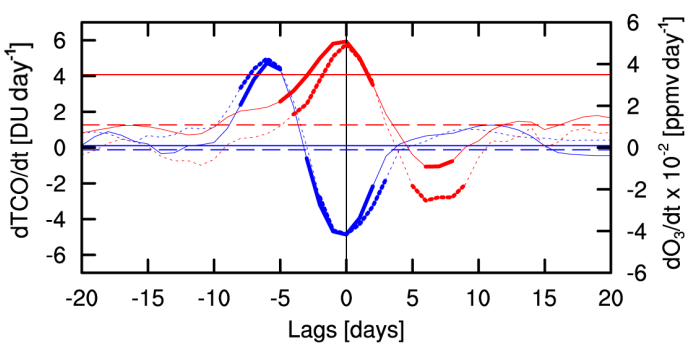

Figure 4. The time evolution of residual mass-stream function anomaly, temperature, and ozone tendencies for the composite of the DWC event (blue lines) and upward wave event (red lines). (a) Residual mass-stream function anomaly and (b) temperature tendency averaged from 100 to $1 \mathrm{hPa}$ and 60 to $90^{\circ} \mathrm{N}$. (c) Total column ozone tendency (solid lines) and mixing ratio ozone tendency (dashed lines) at $50 \mathrm{hPa}$, averaged between $60-90^{\circ} \mathrm{N}$. The horizontal lines indicate the time-integrated significant values of each quantity over the life cycle. The time-integrated values for the upward wave event are divided by 10 for display purposes. Statistical significance at the $95 \%$ level is denoted with thick solid lines based on a 1000-trial Monte Carlo test.

perature is canceled out over the life cycle of the wave, as indicated by the time tendencies that change from being positive to negative (Fig. 4a and b). We also compared the results from the DWC life cycle to the upward wave events. The upward wave event is defined in a similar manner as the DWC event but for the meridional heat flux values above the 95th percentile of the JFM distribution. It is shown that the time integration of both quantities over the life cycle of upward wave events is irreversible over the life cycle (i.e., positive value), with the time tendencies not reversing during the life cycle (Fig. 1c and d and see also Fig. S1 in the Supplement). This means that increased upward wave events result in stronger residual circulation and warmer polar vortex in winter. Thus, the overall effect of having more DWC events 
in winter is to have weaker residual circulation and colder polar vortex (i.e., DWC weakens the typical increase in residual circulation and temperature induced by upward wave events in winter).

Likewise, we also calculated the time-integrated evolution of ozone tendency at $50 \mathrm{hPa}$ and TCO tendency averaged between 60 and $90^{\circ} \mathrm{N}$ for both DWC events (blue lines) and upward wave events (red lines) (Fig. 4c). The results showed that the time integration of the ozone and TCO tendencies over the life cycles of DWC are nearly zero, indicating a reversible impact on ozone (Fig. 4c, horizontal blue lines). Conversely, the time integration of the ozone and TCO tendencies during upward wave events are positive, indicating a net-increased ozone during the life cycle of upward wave events (Fig. 4c, horizontal red lines; see also Fig. S2). Thus, the overall direct effect of having more DWC events in winter is to have lower ozone levels in the polar stratosphere due to weakening of the typical increase in ozone induced by upward wave events.

A complementary analysis of wave-2 heat flux events is shown in the Supplement (Figs. S4 and S5). Overall, the evolution of the wave- 2 events involve weaker heat flux values and weaker EP flux divergence (Fig. S4a and b, consistent with Dunn-Sigouin and Shaw, 2015) and thus result in a weaker connection with the ozone time tendency (Fig. S5). The stratospheric impacts on ozone associated with downward wave- 2 events are not as robust as the corresponding downward wave-1 events (Fig. S5).

\subsection{Simulations of the effect of DWC on ozone}

Determining the connection between DWC, stratospheric residual circulation, and polar temperature is one of the keys to improving our understanding of the link between stratospheric dynamics and ozone variability, both in the real atmosphere and in the stratosphere-resolving chemistry-climate models. In this section, we attempt to test if the linkages between DWC and transient changes in polar stratospheric ozone can be reproduced in the current chemistry-climate model CESM1(WACCM). The larger sample of events in the model also allows us to underpin the findings from the reanalysis dynamics using robust, statistically significant results.

Figure 5 shows the composite life cycle of downward planetary wave events as a function of pressure and time from -20 to +20 days for (a) wave- 1 heat flux anomaly, (b) wave-1 EP flux divergence anomaly, (c) residual circulation anomaly, and (d) total potential temperature tendency in CESM1(WACCM). Consistent with MERRA2, the model simulation showed that the life cycle of DWC events involves a transient reversal of wave-1 heat flux anomaly, wave-1 EP flux divergence anomaly, residual circulation anomaly, and potential temperature tendencies (Fig. 5a). In particular, there is a positive heat flux anomaly prior to DWC events from days -18 to -4 , coinciding with EP flux convergence anomalies in the stratosphere (Fig. 5b). The high-latitude heat flux anomaly evolution coincides with poleward residual circulation anomaly and the corresponding positive potential temperature tendency in the Arctic stratosphere (Fig. 5c and d). We should note that the positive wave- 1 heat flux signal in the model persists longer compared to MERRA2, which is mainly associated with a common model bias in the background circulation that feeds back on the wave dynamics and wave-mean flow interaction (Lubis et al., 2016a). This explains why the evolution of the residual circulation anomaly and the associated temperature tendency in the model last longer prior to the mature stage of DWC.

From days -3 to +3 , the vertical heat flux anomaly subsequently changes sign (Fig. 5a), producing negative wave1 heat flux anomalies in the stratosphere. This negative flux anomaly coincides with a positive residual circulation anomaly and negative temperature tendency in the stratosphere (Fig. 5c and d). The equatorward anomaly of the residual circulation and the associated adiabatic cooling in the stratosphere are again consistent with wave-1 EP flux divergence in the stratosphere due to transient downward wave propagation from the stratosphere to the troposphere (Fig. 5b). Although there is a difference in the timescale of the upward wave pulses prior to DWC events between the model and MERRA2, the model is relatively good in reproducing the evolution of DWC.

Next we examine the effect on ozone tendencies, as was done in Fig. 2. Figure 6 shows the time evolution of total ozone tendencies during the composite life cycle. Consistent with MERRA2, the negative ozone tendency in the model occurs during the time of strongest DWC events (days -3 to +3 ), between 100 and $5 \mathrm{hPa}$ (Fig. 6a). This negative ozone tendency is preceded by a positive ozone tendency (days -20 to -5$)$. These positive ozone tendency values persist longer in the model compared to MERRA2, which is consistent with a more persistent upward wave flux and the associated poleward residual circulation anomalies prior to DWC events in the model. The transition of positive to negative ozone tendency in the lower-to-middle stratosphere is consistent with poleward-to-equatorward residual circulation anomalies (Fig. 5a). Interestingly, there is a strong positive ozone tendency in the upper stratosphere (above $5 \mathrm{hPa}$ ) during the time of maximum DWC events, which is not captured by MERRA2. This discrepancy will be discussed in the following section.

By decomposing the total ozone tendency into dynamical and chemical terms, it is shown that transient changes in ozone dynamics dominate the total ozone tendency during the composite life cycle (Fig. $6 \mathrm{~b}$ and c). In the mid-lower stratosphere, the ozone tendency due to dynamics is mainly attributed to the vertical advection process (Fig. 6d), while in the upper stratosphere both vertical advection and eddy transport effects become equally important (Fig. 6d and f). In particular, a strong positive total ozone tendency in the upper stratosphere during the time of maximum DWC events is at- 

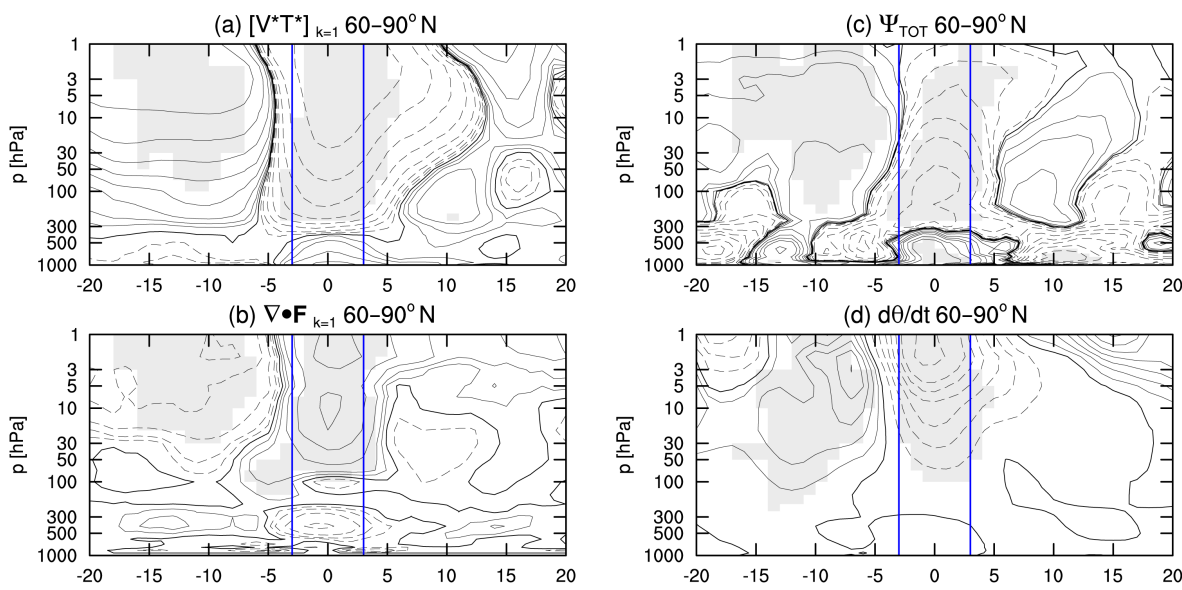

Figure 5. Same as Fig. 1, but from a 100-year CESM1(WACCM) simulation.
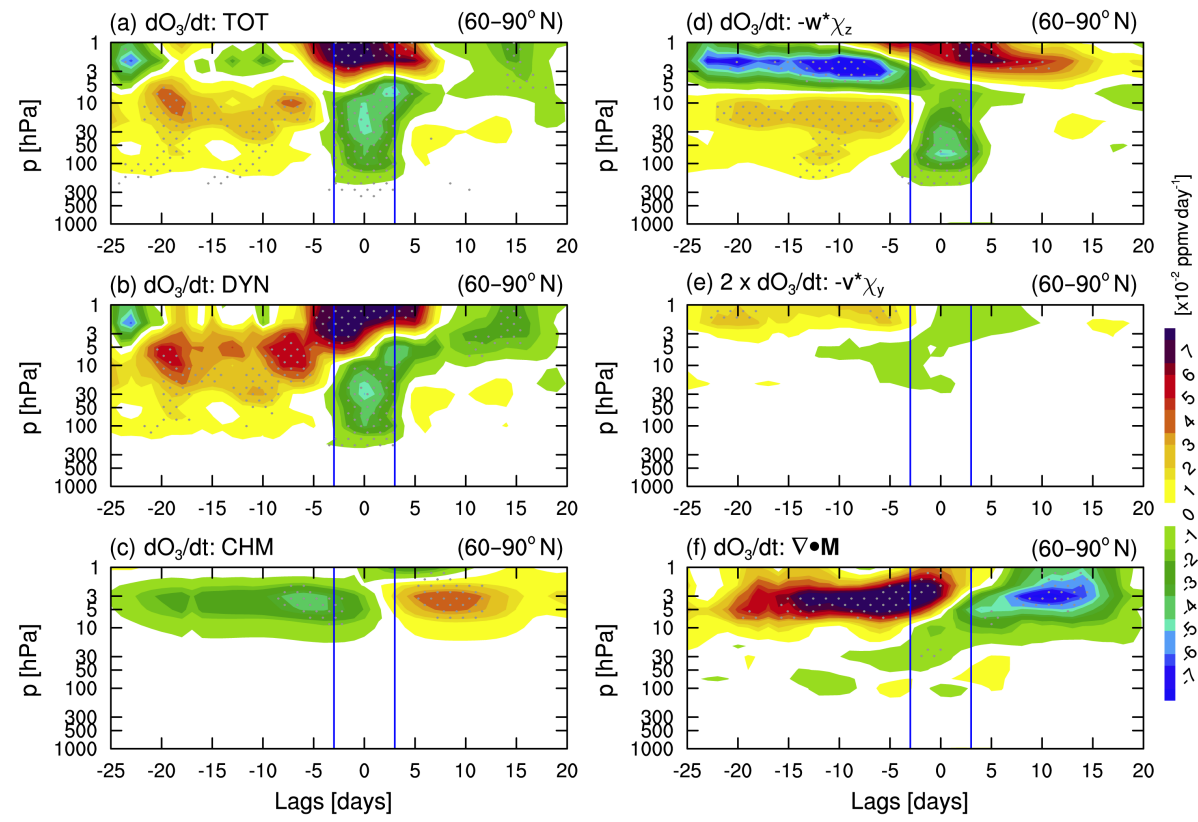

Figure 6. Same as Fig. 2, but from a 100-year CESM1(WACCM) simulation.

tributed to both eddy transport effect and vertical advection process through the residual circulation (Fig. 6f). The magnitude of these two quantities in the model is relatively higher compared to MERRA2 and therefore leads to the large differences in ozone tendency in the upper stratosphere (Fig. 2d and $\mathrm{f}$ vs. Fig. $6 \mathrm{~d}$ and $\mathrm{f}$ ). The detailed analysis of why these model terms are biased is beyond the scope of the current study. Conversely, the ozone tendency due to chemistry in the upper stratosphere is somewhat weaker and in the opposite sign of the ozone tendency due to dynamics (Fig. 6c). The overall results support our observationally based analysis that the transient changes in polar stratospheric ozone during a DWC event are mainly attributed to changes in the dynamical ozone transport.
As with MERRA2, this general relationship between DWC and polar stratospheric ozone in the model simulation can also be assessed through the instantaneous correlation between the two extreme stratospheric wave- 1 heat flux events. Figure 7 shows a similar diagnostic as in Fig. 3, comparing the two-dimensional distribution of the polar-capaveraged ozone tendencies and residual circulation during extreme wave-1 heat flux events. Consistent with MERRA2, the days with positive and negative extremes (red and blue dots, respectively) are systematically skewed compared to the background distribution, so that stronger DWC events correspond to stronger negative ozone tendency and weaker residual circulation (Fig. 7a, $(r=-0.82)$ ). A similar instantaneous correlation is found between dynamical ozone ten- 

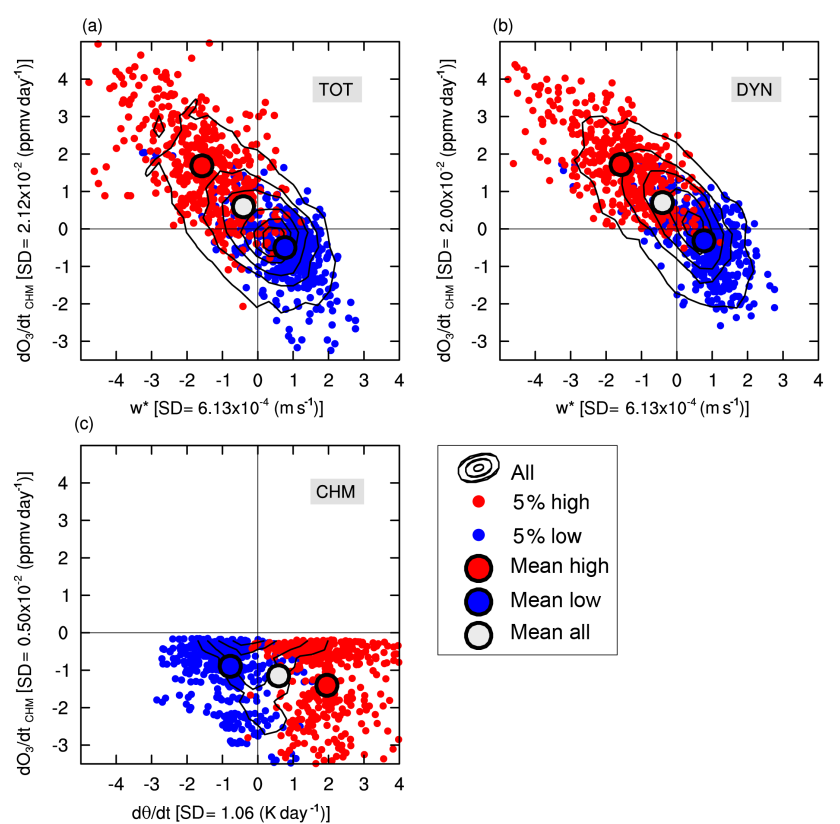

Figure 7. Same as Fig. 3, but from a 100-year CESM1(WACCM) simulation.

dency and $w^{*}(r=-0.85)$, but not for the ozone tendency due to chemistry $(r=-0.11)$. This is again consistent with the observationally based analysis that the polar mid-lower stratospheric ozone during the DWC life cycle is instantaneously linked to changes in dynamical ozone transport.

As a last step, the direct cumulative effects of DWC on residual circulation, temperature tendency, and ozone were analyzed (Fig. 8). We first analyzed the time integration of the residual circulation anomaly and polar temperature tendency during the composite life cycle of the wave (Fig. 8a and b). It is shown that the impacts on both residual circulation and potential temperature tendency over the life cycle of DWC events are reversible, consistent with MERRA2. We note, however, that there are differences in the values of potential temperature tendency between the model and MERRA2. The relatively larger values of the potential temperature tendency in the model are likely associated with the modeled temperature bias, which is a common problem in chemistry-climate models (CCMs) (Austin and Butchart, 2003; Eyring et al., 2010). WACCM still exhibits a bias in the stratospheric westerly jets and polar temperatures in the $\mathrm{NH}$ winter, where the largest biases in the stratosphere are in the location of the maximum of the NH westerly jet (Marsh et al., 2013). Nevertheless, the model results generally support the observationally based analysis with MERRA2 that the DWC event acts to dampen the typical strengthening of residual circulation and the associated adiabatic warming induced by upward planetary waves. (a) $\Psi_{\text {TOT }}\left[100-1 \mathrm{hPa}, 60-90^{\circ} \mathrm{N}\right]$

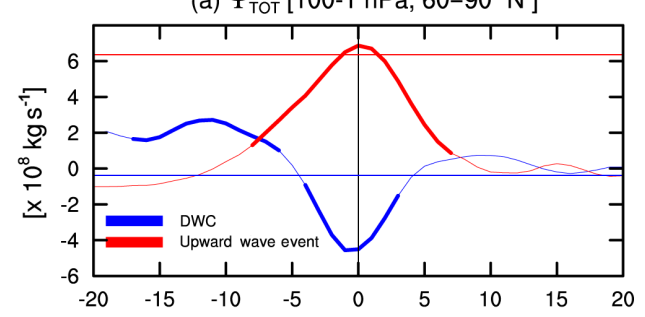

(b) $\mathrm{d} \theta / \mathrm{dt}\left[100-1 \mathrm{hPa}, 60-90^{\circ} \mathrm{N}\right]$

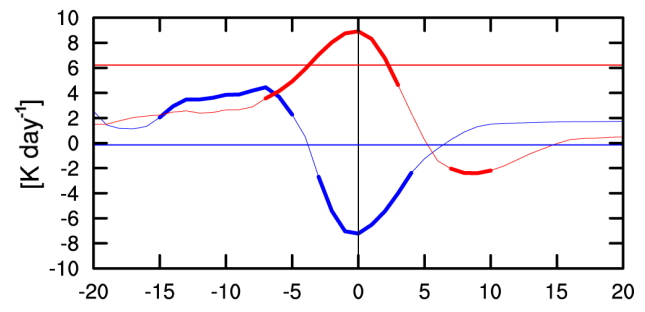

(c) dTCO/dt (solid) \& $\mathrm{dO}_{3} / \mathrm{dt}$ at $50 \mathrm{hPa}$ (dashed)

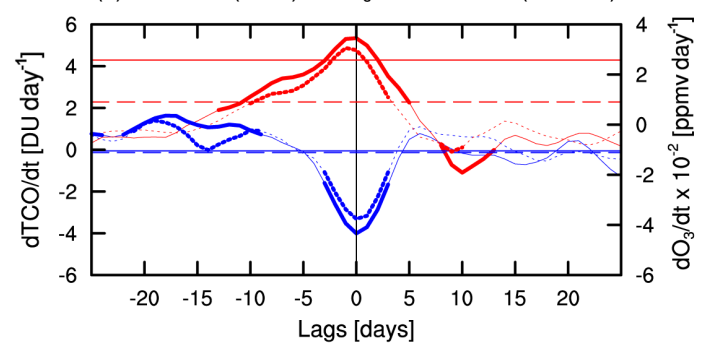

Figure 8. Same as Fig. 4, but from a 100-year CESM1(WACCM) simulation.

Furthermore, the direct cumulative effects of DWC events on ozone in the model were examined in the same way as in Fig. $8 \mathrm{a}$ and $\mathrm{b}$. The time evolution of TCO tendency and ozone tendency at $50 \mathrm{hPa}$ averaged between 60 to $90^{\circ} \mathrm{N}$ for the composite of the DWC event (blue lines) and upward wave event (red lines) are shown in Fig. 8c. Confirming the results from MERRA2, the time integration of significant TCO and ozone tendencies is zero, indicating a reversible impact on the ozone (Fig. 8c, blue lines). However, the positive ozone tendency values prior to DWC events persist longer in the model compared to MERRA2, which is consistent with the persistent positive heat flux and poleward residual circulation anomalies. Further study is therefore still required to understand the bias in the ozone magnitude in the model prior to a DWC event. Conversely, the time integration of the significant TCO and ozone tendencies during upward wave events are positive, indicating a net increase in ozone (Fig. 8c, red lines). The overall results are consistent with our previous findings using MERRA2, showing that the direct effect of the full wave reflection life cycle is to weaken the typical increase in ozone due to upward planetary wave events. 
Table 2. The reflective and absorptive years defined based on the vertical reflecting surface $(m<0)$ and $U_{30 \mathrm{hPa}}$ in JFM.

\begin{tabular}{lll}
\hline Data & Reflective & Absorptive \\
\hline MERRA2 & $1982,1986,1990,1993,1994,1995,1997$, & $1979,1981,1984,1985,1999,2001,2004$, \\
& 2011 & $2008,2009,2010,2013$ \\
\hline CESM1(WACCM) & $1958,1964,1966,1967,1968,1969,1971,1972$, & $1956,1957,1960,1965,1970,1975,1978,1979$, \\
& $1974,1982,1984,1985,1986,1990,1991,1994$, & $1980,1981,1988,1989,1992,1995,2002,2014$, \\
& $1998,2004,2005,2011,2019,2024,2028,2030$, & $2017,2018,2020,2023,2026,2027,2032,2036$, \\
& $2033,2035,2042,2045,2047,2049$ & $2038,2043,2044,2046,2048,2052,2054$ \\
\hline
\end{tabular}

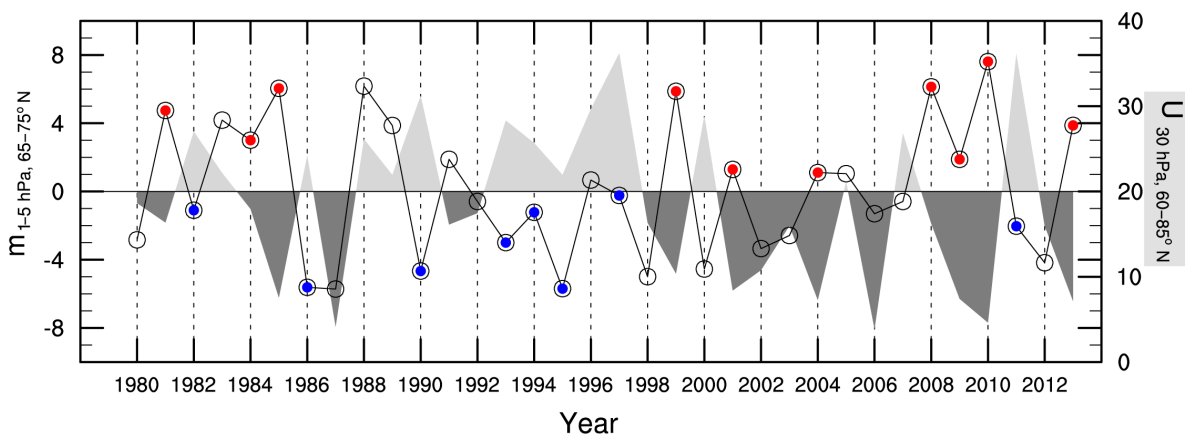

Figure 9. Time series of seasonal (JFM) mean of $m$ (line) and U30 (shading). The blue (red) asterisk indicates the reflective (absorptive) winters defined based on vertical wave numbers and mid-stratosphere zonal mean wind (further discussed in the text).

\section{Seasonal impact of DWC on ozone}

The former analysis shows that an individual DWC event has a statistically significant impact on the polar stratospheric ozone. While the impact of an individual event occurs on a short timescale, several events in an individual JFM season may produce an impact on a longer timescale. In this section, we briefly examine the cumulative impacts of DWC on ozone during seasons that are dominated by DWC events.

\subsection{Reflective vs. absorptive winters}

In order to analyze the seasonal impact of DWC on polar stratospheric ozone, we classify winters as reflective and absorptive based on the basic state of the stratosphere characterized by the formation of reflecting surface and the strength of the polar vortex, whereas previous study used cumulative wave-1 heat flux definition (Shaw and Perlwitz, 2013). Our classifications are based on the vertical wave number $(m)$ (averaged between $1-5 \mathrm{hPa}$ and $65-75^{\circ} \mathrm{N}$ ) and zonal mean wind at $30 \mathrm{hPa}(U 30)$ (averaged between 60 and $85^{\circ} \mathrm{N}$ ) in winter months (JFM), similar to Perlwitz and Harnik (2003) and Harnik (2009). The vertical wave numbers $(m)$ are calculated using the wave geometry diagnostic of Harnik and Lindzen (2001), which separates the more commonly used index of refraction (see Charney and Drazin, 1961) into vertical and meridional wave number contributions. The wave numbers are diagnosed from the solution to the wave equation associ- ated with the conservation of potential vorticity in spherical coordinates (see Appendix B4).

Reflective winters (with dominant DWC events) are defined when $m<0$ and $U 30>2.5$ standard deviation $(\sigma)$ of all JFM months, while absorptive winters (with dominant upward wave events) are defined when $m>0$ and $U 30<2.5 \sigma$. We note that $m<0$ often occurs during or after sudden warming events. Thus, in defining a reflection index based on $m$, we only look at negative $m$ events for which winds in the lower stratosphere remain strong (Harnik, 2009). Therefore, we exclude the years with SSW events from the potential reflective winters in contrast to the wave- 1 heat flux definition of Shaw and Perlwitz (2013) where SSWs are included. We note, however, that the two definitions of reflective (absorptive) winters give similar results. In both cases reflective (absorptive) winters are dominated by a large number of extreme negative (positive) heat flux events (see Fig. S7). However, the resulting polar stratospheric temperature response is weaker for the wave-1 heat flux definition due to the inclusion of SSWs (not shown). The time series of selected reflective and absorptive winters are shown in Fig. 9. Using this definition, we found the most reflective (absorptive) winters: 8 (11) in MERRA and 30 (29) in CESM1(WACCM) (see Table 2).

Figure 10 shows composites of the zonal-mean wind, wave-1 geopotential height, and temperature difference in JFM for the composite of reflective and absorptive winters in MERRA2 and in CESM1(WACCM). During reflective win- 

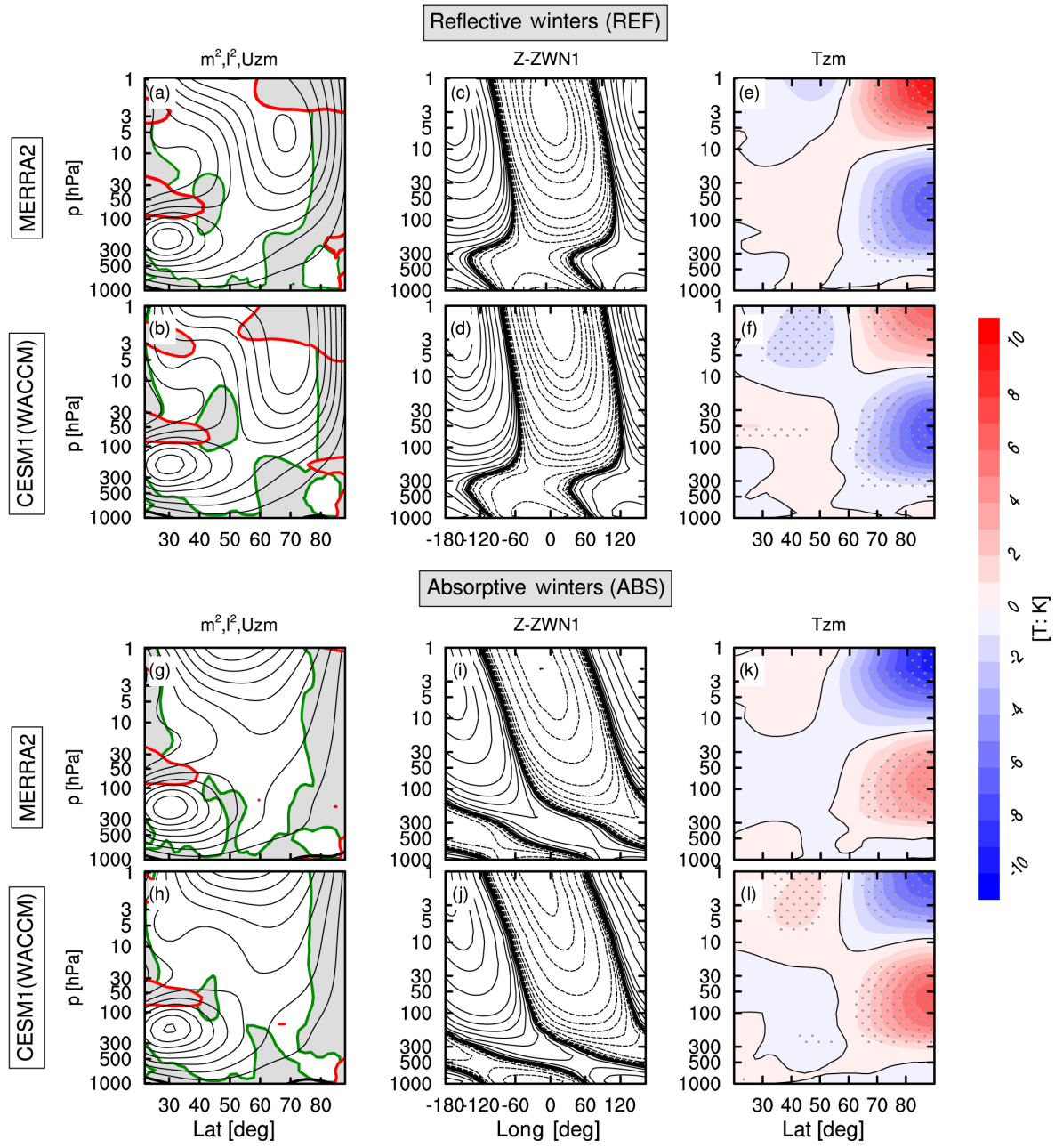

Figure 10. Composites of the zonal-mean zonal wind, wave-1 geopotential height, and temperature mean differences for reflective (REF) and absorptive (ABS) winters in JFM from MERRA2 and CESM1(WACCM). (a, b, g, h) The zonal-mean zonal wind (black contour lines) superimposed with vertical and meridional wave numbers (red and green contour lines). The gray shading indicates regions of wave evanescence and the red (green) contour line indicates the vertical reflecting surface $m^{2}=0$ (meridional wave guide $l^{2}=0$ ). Contour interval for the zonal mean wind is $5 \mathrm{~m} \mathrm{~s}^{-1}$. (c, $\left.\mathbf{d}, \mathbf{i}, \mathbf{j}\right)$ The wave- 1 geopotential heights averaged between 60 and $70^{\circ} \mathrm{N}$; contour interval is logarithmic powers of $2: \pm[0.5,1,2,4,8,16,32,64,128,256, \ldots] \mathrm{m} .(\mathbf{e}, \mathbf{f}, \mathbf{k}, \mathbf{l})$ The zonal mean temperature differences (REF or ABS minus the 1980 2013 climatological mean). Blue (red) contours indicate cooler (warmer) regions compared to the climatology. The contour interval is $1 \mathrm{~K}$. The stippling indicates differences significant at the $95 \%$ confidence level.

ters, the maximum zonal-mean zonal wind resides in the midstratosphere, and consequently the region of vertical reflecting surface extends down to $3 \mathrm{hPa}$ (Fig. 10a and b). There is also a clear meridional waveguide below $10 \mathrm{hPa}$ between 50 and $80^{\circ} \mathrm{N}$, which channels the reflected wave activity to the high-latitude troposphere (essentially preventing dispersion of the waves in the meridional direction before they reach the mid-troposphere). This vortex configuration is favorable for DWC events, which is indicated by an eastward phase tilt with heights of the wave-1 structure from the midtroposphere to the lower stratosphere (Fig. 10c and d). In addition, the Arctic mid-lower stratosphere is significantly colder; the polar cap temperature at $50 \mathrm{hPa}$ is $6 \mathrm{~K}$ lower than the climatological mean in MERRA2 (Fig. 10e) and is approximately $7 \mathrm{~K}$ colder in the model. This cooling is consistent with a strong (undisturbed) polar vortex, which is associated with less wave absorption in the stratosphere due to mainly enhanced DWC events or to a lack of upward wave propagation from the troposphere.

In contrast, during absorptive winters, waves can propagate all the way up through the stratosphere because the reflecting surface vanishes, meaning the vortex tends to be weaker due to more wave deceleration (Fig. $10 \mathrm{~g}$ and $\mathrm{h}$ ). The meridional waveguide occurs below $30 \mathrm{hPa}$ between 50 and $80^{\circ} \mathrm{N}$, allowing more upward planetary wave propagation from the troposphere to penetrate in the stratosphere. This 

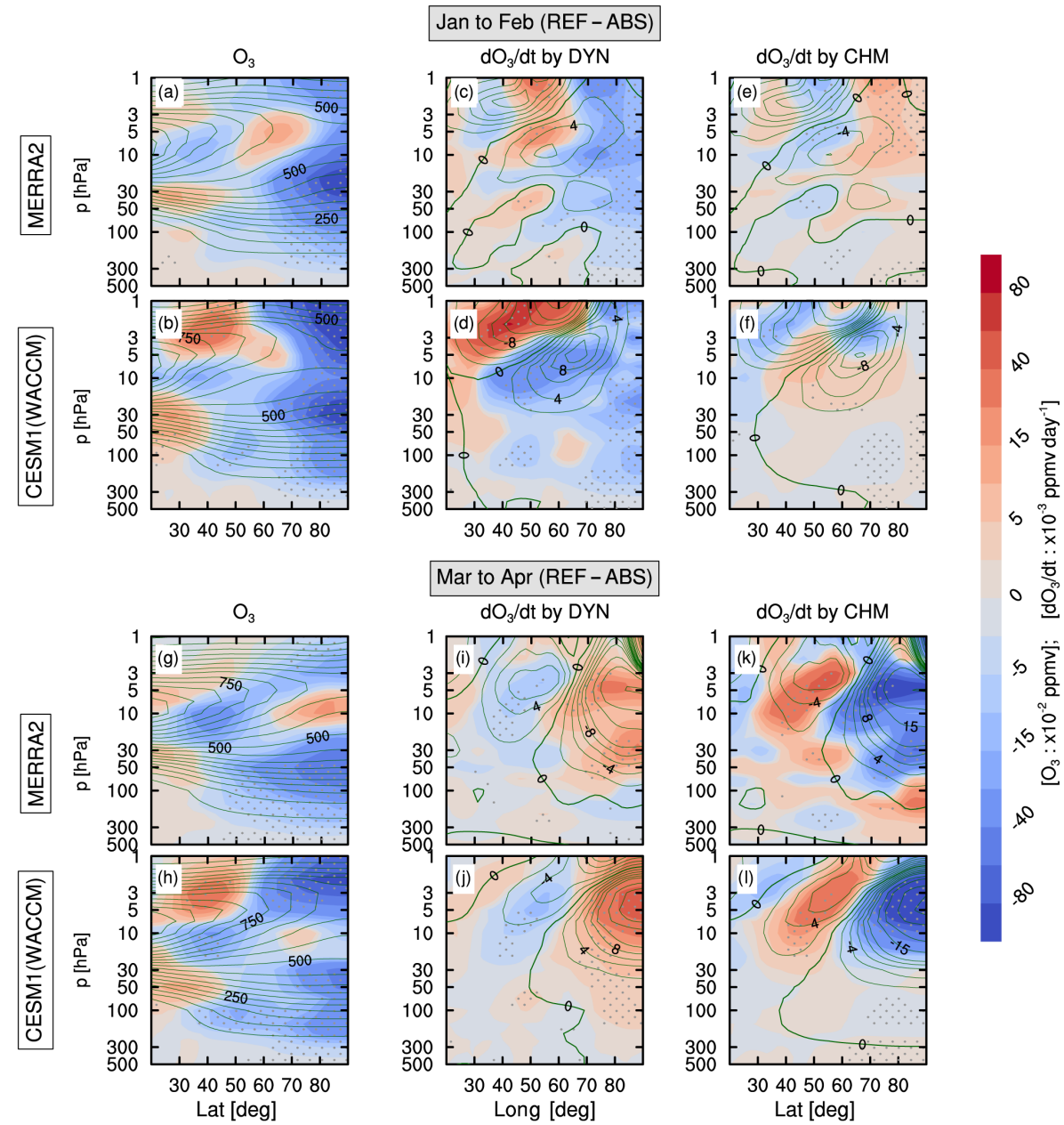

Figure 11. Composite-mean difference (REF minus ABS) of the (a, $\mathbf{b}, \mathbf{g}, \mathbf{h})$ zonal mean ozone, $(\mathbf{c}, \mathbf{d}, \mathbf{i}, \mathbf{j})$ ozone tendency due to dynamics, and $(\mathbf{e}, \mathbf{f}, \mathbf{k}, \mathbf{l})$ ozone tendency due to chemistry averaged between January-February and March-April, from MERRA2 and CESM1(WACCM). The climatological mean values are denoted by green contour. The contour lines for this plot have increments of 50 units for total ozone and 2 units for ozone tendency. The solid (dashed) lines indicate positive (negative values). The zero contour lines are plotted in thick dark green. Stippling denotes differences significant at the $95 \%$ confidence level.

configuration is favorable for upward wave events, indicated by the westward phase tilt with height of the wave-1 structure from the lower troposphere to the upper stratosphere (Fig. 10i and j). The Arctic mid-lower stratosphere is significantly warmer, by approximately $4 \mathrm{~K}$ higher than the climatological mean at $50 \mathrm{hPa}$ in MERRA2 (Fig. 10k) and by about $6 \mathrm{~K}$ warmer in the model (Fig. 101). The warmer and more disturbed polar vortex during absorptive winters is consistent with enhanced waves propagating upward from the troposphere into the stratosphere, resulting in stronger wavemean flow interaction.

\subsection{Seasonal impact on ozone in winter and spring}

In order to estimate the seasonal impacts of DWC events on ozone, we analyzed ozone differences between reflective and absorptive seasons for midwinter (January-February) and late winter-early spring (March-April) in MERRA2 and CESM1(WACCM) (Fig. 11). Here, we recall the reflective seasons (i.e., winters dominated by DWC events) as REF and the absorptive seasons (i.e., winters dominated by upward wave events) as ABS.

The results show that the seasonal effects of DWC leads to a reduction of ozone concentration in the stratosphere during midwinter (Fig. 11a and b) and early spring (Fig. 11g and $h)$. These results are in agreement with our analysis over the life cycle of DWC showing that (1) a reversible reduction of poleward residual circulation induced by a DWC event weakens the typical increase in ozone induced by an upward wave event during midwinter (the direct effect of DWC) and (2) the cold polar vortex in midwinter due to DWC events results in more ozone loss during early spring (the indirect effect of DWC). To distinguish between the two effects quantitatively, we examine the contribution of dynamics and chem- 
istry terms to the mean differences between the two types of winters (i.e., REF minus ABS). We note that responses of ozone and ozone tendency in REF and ABS winters are symmetric with respect to the climatological mean, meaning that ABS and REF anomalies (relative to climatology) are similar but opposite to each other (see Figs. S8 and S9). The results showed that a reduction of ozone concentration during midwinter in REF is mainly maintained by negative ozone tendency due to dynamics, in both MERRA2 (Fig. 11a) and model simulation (Fig. 11b). This is consistent with the direct impact of DWC on ozone in midwinter, where the reversible impact of DWC on ozone over the life cycle leads to less ozone increase in the Arctic. Conversely, there is a positive chemically driven ozone anomaly in the upper stratosphere during midwinter (Fig. 11e). This positive anomaly is likely associated with less chemical ozone loss in the upper stratosphere due to decreased temperature (cold) in REF during midwinter. However, we found that this positive ozone tendency anomaly due to chemistry is relatively small compared to those from the dynamics, so that the total net effect of DWC on ozone is still negative. In summary, the results showed that the accumulative impact of DWC on ozone during midwinter leads to less ozone transport to the polar region (see also Figs. S9c and S10c).

During early spring, the lower ozone concentration in REF compared to ABS in the upper stratosphere (between 3 and $1 \mathrm{hPa}$ ) and in the lower-to-middle stratosphere (between 100 and $50 \mathrm{hPa}$ ) (Fig. 11g and h) is mainly maintained by negative ozone tendency due to chemistry terms (Fig. 11k and 1). This is consistent with the indirect impact of DWC on ozone, which leaves the polar vortex cold in midwinter (i.e., dampening the typical warming induced by upward wave events in winter; Figs. 1f and 5f), and thus resulting in more ozone destruction in spring due to more accumulation of ODS on polar stratospheric clouds. This is also consistent with a strong polar vortex associated with increased DWC events (Fig. 10a and b). Comparing the ozone tendency due to chemistry in REF to the climatological mean values, we found that the indirect accumulative impact of DWC in spring results in an increase in seasonally averaged chemical ozone loss (see Figs. S8k, 1 and S9k, 1). The aforementioned indirect effect of DWC should only affect ozone concentration in spring when the polar stratosphere becomes sunlit. Moreover, we also note that there is a positive dynamical ozone tendency anomaly in late winter (Fig. 11i and j) resulting from the opposite responses of dynamical ozone tendency in REF and ABS during late winter (Figs. S8i, j and $S 9 i, j$ ). The increased ozone tendency due to dynamics in REF is likely associated with the occurrence of early final warming events (Fig. S10), allowing more waves to break into the stratosphere in late winter and thus enhancing the dynamical ozone transport to the pole during this period. However, since the contribution from chemistry is dominant during REF, the total net effect of DWC on ozone is still negative (i.e., less ozone concentration), which is expected during re- flective winters. In contrast, during ABS, the final warming is delayed until late spring, resulting in less dynamical ozone transport to the pole during late winter (Fig. S10). This behavior is consistent with the previous observational studies (e.g., Hu et al., 2014), showing that early spring final warming events, which on average occur in early March, tend to be preceded by non-SSW winters (i.e., typical of a REF winter), while late spring final warming events, which on average take place up until early May, are mostly preceded by SSW events in midwinter (typical of an ABS winter).

\section{Conclusions and discussion}

The goal of this study was to investigate the impact of DWC on polar stratospheric ozone in order to fully understand the mechanisms controlling the variability of Arctic stratospheric ozone. The key results of this study are as follows:

1. The impact of DWC on the residual circulation and on potential temperature tendency is reversible over the life cycle, as indicated by the time tendencies that change from being positive to negative. Thus, the overall effect of having more DWC events in winter is to have a weaker residual circulation and colder polar vortex (i.e., DWC weakens the typical increase in residual circulation and temperature induced by upward wave events in winter).

2. A direct effect of DWC events on ozone, via advection to the pole by the induced residual circulation, is reversible, suggesting that DWC weakens the typical increase in ozone due to upward planetary wave events in winter. This is consistent with a stronger transport of ozone to the pole during upward planetary wave events in the absence of DWC events.

3. An indirect effect of DWC events, via a cooling of the winter polar vortex as a result of the reversible impact of DWC on the polar temperature tendency over the life cycle, leads to increased springtime ozone loss through heterogeneous chemical processes.

4. Winter seasons dominated by DWC events (i.e., reflective winters) are characterized by a lower stratospheric ozone concentration in winter and spring. This behavior is consistent with the cumulative effects of downward planetary wave events on polar stratospheric ozone via the residual circulation and the polar temperature in winter.

Our results establish a new perspective on dynamical processes controlling Arctic ozone variability. Previous studies have shown that variations in upward planetary waves entering the lower stratosphere in midwinter determine the magnitude of ozone loss in the Arctic polar vortex (e.g., Randel et al., 2002; Newman et al., 2001; Weber et al., 2003; 
(a) Absorptive stage

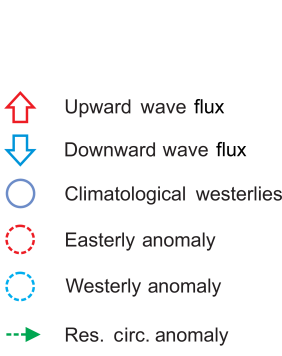

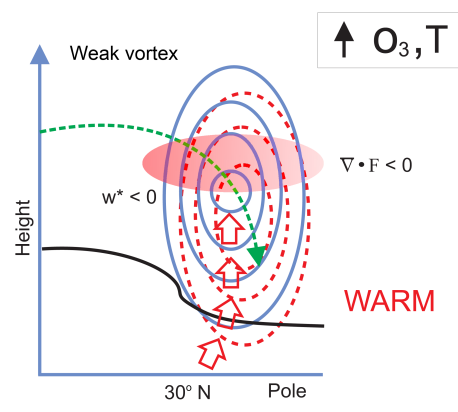

(b) Reflective stage
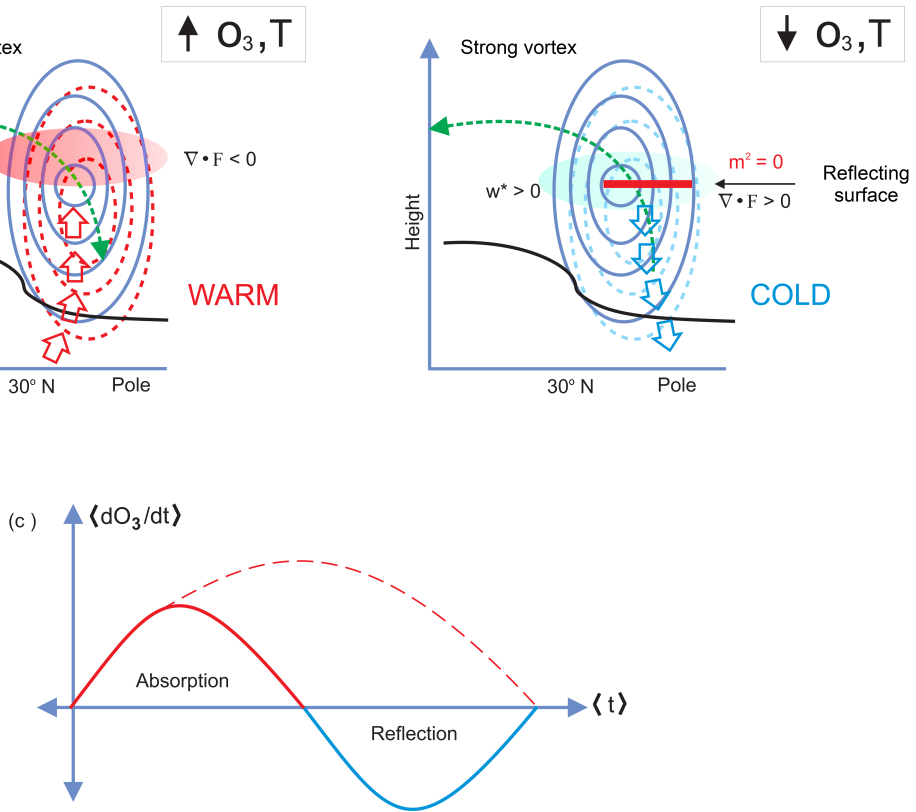

Figure 12. Schematic presentation of the DWC influence on polar stratospheric ozone over the life cycle of DWC: (a) upward absorption stage of the wave life cycle, (b) downward reflection stage of the wave life cycle, with reversed tendencies. The red (blue) shading indicates a negative (positive) anomaly in EP flux divergence. (c) The associated time evolution of ozone tendency over the life cycle of DWC, where the absorptive and reflective stages are denoted by the red and blue solid lines, respectively. In contrast, the evolution of ozone tendency associated with the life cycle of upward wave events, which consist only of a longer absorption stage, is denoted by the red dashed line.

Tegtmeier et al., 2008). In particular, these studies showed that weaker midwinter planetary wave forcing in the stratosphere due to weaker upward wave propagation leads to lower spring Arctic temperatures, and thus to more ozone destruction in spring. Our results suggest that weaker planetary wave forcing in the stratosphere can also be attributed to enhanced DWC events in the presence of the vertical reflecting surface. This leads to positive EP flux divergence in the stratosphere, leading to less ozone transport in early winter and more ozone destruction in spring. A schematic presentation of the DWC influence on polar stratospheric ozone over the life cycle of the wave is shown in Fig. 12. During an upward absorption stage of the wave life cycle, the transport of ozone to the pole increases due to strong wave deceleration induced by upward wave propagation (Fig. 12a and c). The stronger residual circulation causes anomalous adiabatic warming over the pole due to air being advected downward. Conversely, during a downward reflection stage, increased DWC events in the presence of a vertical reflecting surface leads to a positive divergence of the EP flux in the stratosphere, resulting in a weaker residual circulation in winter and thus less ozone transport to the pole (Fig. 12b and c). Therefore, the overall direct effect of DWC on ozone is canceled out (reversible) over the life cycle, suggesting that DWC events weaken the typical increase in ozone due to upward wave events in winter. In addition, since the polar vor- tex is cold and strong during a reflective winter, more ozone destruction will occur in spring due to heterogeneous chemical processes. Our results suggest that lower polar stratospheric ozone levels in midwinter and in spring can occur if the DWC events dominate the upward wave events in the Arctic winter stratosphere.

Recent studies showed that large chemical ozone loss in the spring of 2011 is one of the major reasons for the unprecedented low Arctic column ozone (e.g., Manney et al., 2011; Isaksen et al., 2012; Hommel et al., 2014). This is attributed to extremely low midwinter temperatures in the lower stratosphere resulting from weaker midwinter planetary wave forcing (Hurwitz et al., 2011). Shaw et al. (2014) hypothesized that the extreme negative eddy heat flux events observed during March 2011 could contribute to ozone loss via a weakening of the residual circulation, which leads to weakened transport, a lowering of Arctic temperatures, and thus large springtime ozone loss. Our results confirmed this by showing that a lower ozone concentration in midwinter and early spring during reflective years is associated with both a weakening of ozone transport and an increase in springtime ozone loss induced by DWC events. Since winter of 2011 is classified as a reflective winter - characterized by a vertical reflecting surface and strong polar vortex due to increased negative heat flux extremes - the lower Arctic col- 
umn ozone in 2011 can thus also be attributed to enhanced DWC events.

Our results also reveal that the amount of wave absorption directly influences polar Arctic temperatures and therefore the amount of ozone destruction in spring. Since wave absorption is minimal during reflective winters, the winters tend to be cold with more ozone destruction. The process of wave reflection and absorption is highly variable, and the amount and location depends on the tropospheric source of the waves, the structure of the vortex on which the waves propagate, and on non-conservative effects (McIntyre and Palmer, 1983; Harnik and Lindzen, 2001; Harnik and Heifetz, 2007). Therefore, a better understanding of the tropospheric and stratospheric conditions that lead to such events is needed to improve our understanding of the link between stratospheric dynamics and ozone variability.
A recent multi-model intercomparison of CCMs concludes that the models do not produce a consistent prediction of the evolution of Arctic temperatures and ozone loss in the 21 st century, mainly because of discrepancies in the model's dynamics (SPARC CCMVal, 2010, Chapter 4). Understanding the impact of DWC events on polar stratospheric ozone and temperatures could provide a useful diagnostic for validating the influence of stratospheric dynamics on springtime column ozone in coupled CCMs.

\section{Data availability}

Reanalysis data used in this paper are publicly available from the GES DISC for the MERRA and MERRA-2 products. The CESM1(WACCM) model data requests should be addressed to Katja Matthes (kmatthes@geomar.de). 


\section{Appendix A: Ozone profiles in MERRA2}

The Aura Microwave Limb Sounder (MLS) ozone product (Waters et al., 2006) from 2005 to 2013 was used to validate the quality of ozone data from MERRA2. Figure A1a and b show the vertical profiles of zonal mean ozone mixing ratios in MERRA2 and MLS averaged between 60 and $90^{\circ} \mathrm{N}$ for (left panel) annual and (right panel) winter JFM means, from 2005 to 2013. It can be seen that the vertical profile of ozone mixing ratios, both mean (contour) and ranges (shading) in MERRA2, shows a reasonable agreement with MLS data from the lower-to-middle stratosphere. Above $3 \mathrm{hPa}-$ where photochemical processes become more dominant both the mean and the spread in MERRA2 slightly deviate from the MLS, which is likely associated with model ozone biases in MERRA2 due to a simplified (parameterized) ozone chemistry used in the GEOS-5 model (Bosilovich et al., 2015). Furthermore, we also confirm that there are no major differences between the MERRA2 and MLS total column ozone climatologies (Fig. A1c). As shown by the solid red line and spreads in Fig. A1c, the MERRA2 total column ozone differs very little from MLS.

Figure A2 shows the differences between the daily total ozone and the ozone anomaly time series in MERRA1 and MERRA2 relative to MLS from 2005 to 2013. It is shown that a positive bias of total ozone mixing ratio in MERRA1 in the lower-to-middle stratosphere (between 100 and $5 \mathrm{hPa}$ ) no longer exists in MERRA2 (Fig. A2d and e). There is also good improvement in total ozone mixing ratio in the upper stratosphere, as indicated by a significant reduction of negative ozone bias in MERRA2 in comparison to MERRA1. Likewise, ozone anomaly in MERRA2 is in a good agreement with the MLS dataset compared to MERRA1 (Fig. A2i and $\mathrm{j}$ ). In summary, we find that the ozone dataset from MERRA2 is significantly improved compared to MERRA1 (Rienecker et al., 2011) (see Fig. A2), and thus the analysis based on this dataset is meaningful and more reliable. (a) $\mathrm{O}_{3}$ annual mean
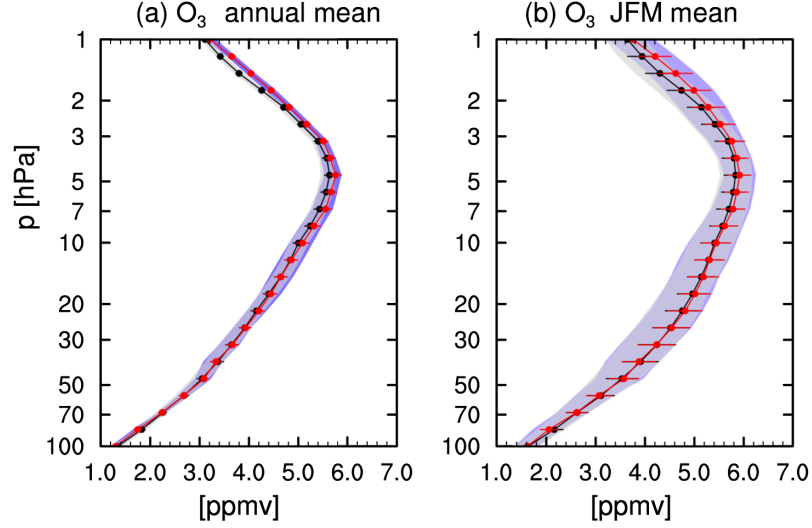

(c) $60-90^{\circ} \mathrm{N}$ column $\mathrm{O}_{3}$

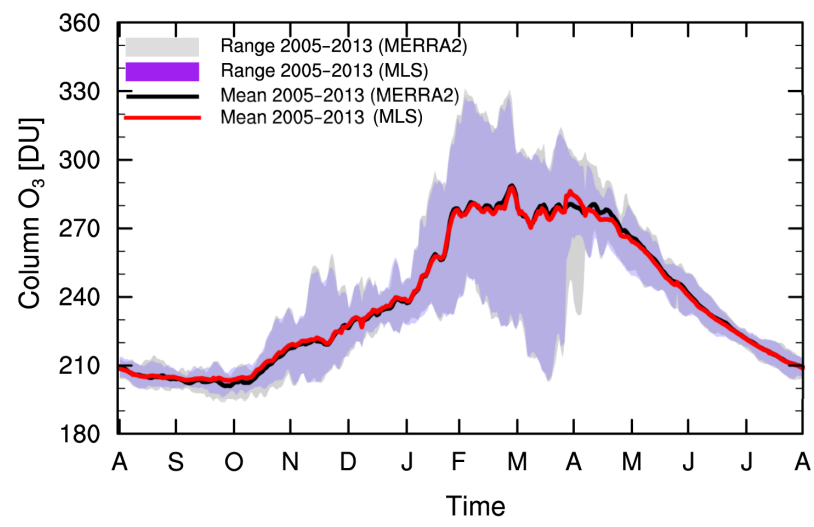

Figure A1. (a, b) Vertical profile of zonal mean ozone (ppmv) from MERRA2 and AURA MLS averaged between 60 and $90^{\circ} \mathrm{N}$ for (left panel) annual and (right panel) winter JFM means. (c) Daily climatology of total column Arctic ozone (vertically integrated from 100 to $1 \mathrm{hPa}$ ) in Dobson units (DU). The solid black (red) curve denotes the climatological mean of MERRA2 (AURA MLS) ozone, and the gray (purple) shading indicates the range from MERRA2 (AURAMLS) for the 2005-2013 time period. 

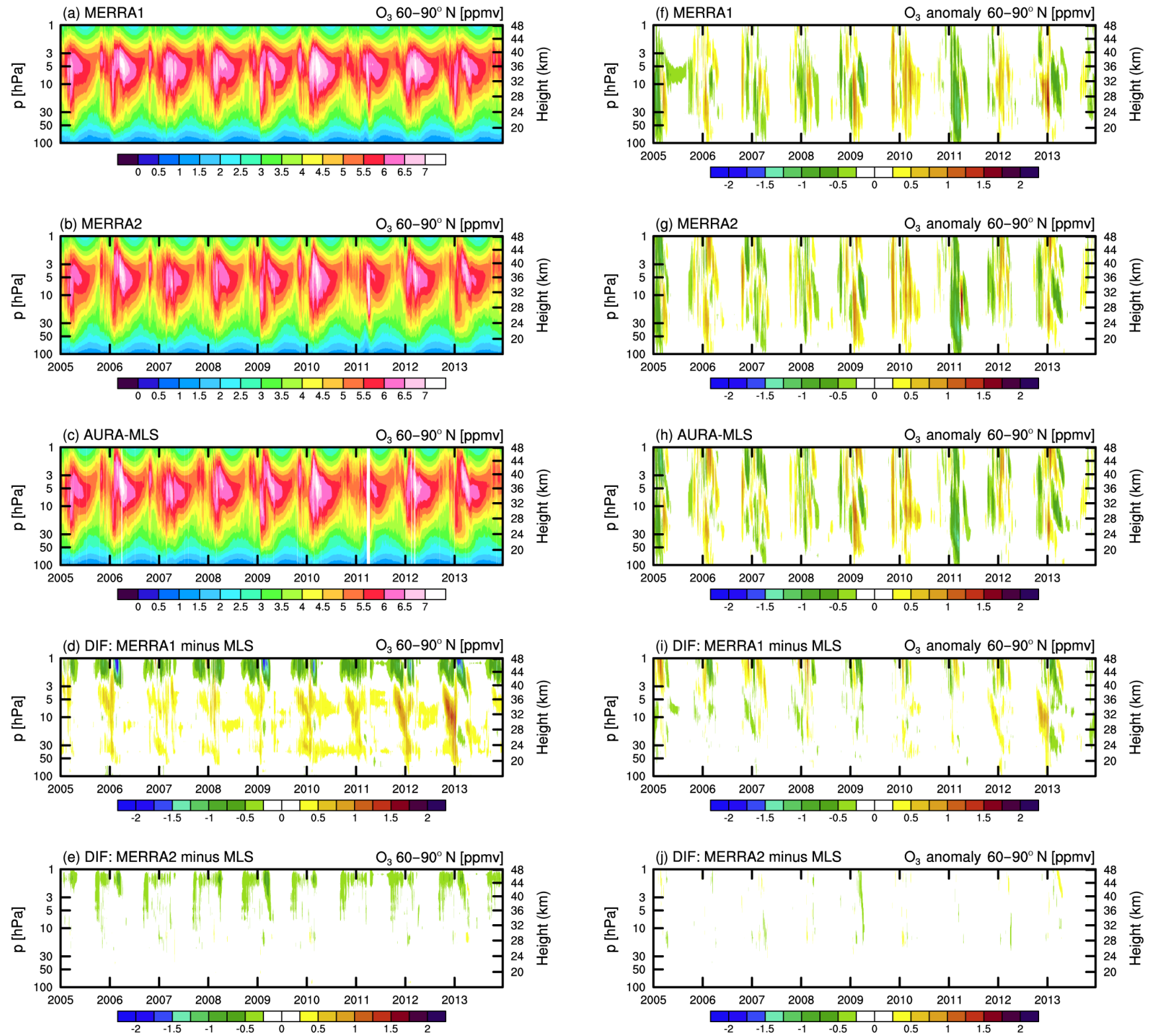

Figure A2. Time series of total ozone (left column panels) and ozone anomaly (right column panels) averaged between 60 and $90^{\circ} \mathrm{N}$ as a function of height and time for (a,f) MERRA-1, (b, g) MERRA2, and (c, h) AURA MLS datasets from 2005 to 2013. Also plotted, the total ozone and ozone anomaly differences between MERRA-1 and AURA MLS (d and i, respectively) and the differences between MERRA2 and AURA MLS (e and i, respectively). 


\section{Appendix B: Residual-mean circulation and wave geometry diagnostics}

Understanding how circulation is controlled by planetary waves is the key to connecting the wave driving to polar temperatures and transport of trace gases such as ozone. The transformed Eulerian mean formulation (Andrews et al., 1987) can be used to directly examine wave effects on the circulation and ozone transport to the polar vortex (Fusco and Salby, 1999; Plumb, 2002; Lubis et al., 2016b). The residual mean circulation is calculated from the stream function $(\Psi)$ of the residual TEM meridional $\bar{v}^{*}$ and vertical $\bar{w}^{*}$ winds as follows:

$$
\left(\bar{v}^{*}, \bar{w}^{*}\right)=\frac{1}{\rho_{\mathrm{o}} \cos \phi}\left(-\Psi_{z}, \frac{1}{a} \Psi_{\phi}\right),
$$

and hence,

$$
\Psi^{*}=\rho_{\mathrm{o}} \cos \phi \int_{z}^{\infty} \bar{v}^{*} e^{-z / H} \partial z .
$$

The residual mass stream function $\Psi_{m}^{\dagger}$ (units in $\mathrm{kg} \mathrm{s}^{-1}$ ) we obtain by

$$
\Psi_{\mathrm{m}}^{\dagger}=(2 \pi a) \rho_{\mathrm{o}} \cos \phi \int_{z}^{\infty} \bar{v}^{*} e^{-z / H} \partial z,
$$

where $\Psi_{\mathrm{m}}^{\dagger} \rightarrow 0$ as $z \rightarrow \infty$

Furthermore, in order to diagnose vertical reflecting surfaces and meridional wave guides for stratospheric planetary wave propagation, the index of refraction $\left(n^{2}\right)$ is separated into contribution from meridional and vertical wave numbers using a quasi-geostrophic $(\mathrm{QG})$ potential vorticity (PV) equation on a $\beta$ plane, with a specified zonal wave number $(k)$ and phase speed $(c)$, as follows (see Harnik and Lindzen, 2001; Lubis et al., 2016a, for details):

$$
\begin{aligned}
n^{2}= & \frac{N^{2}}{f^{2}}\left\{\frac{\bar{q}_{y}}{\bar{u}-c}-k^{2}+f^{2} \frac{e^{z / 2 H}}{N}\left(\frac{e^{-z / H}}{N^{2}}\left(e^{z / 2 H} N\right)_{z}\right)_{z}\right\} \\
& \equiv m^{2}+\frac{N^{2}}{f^{2}} l^{2},
\end{aligned}
$$

where $\bar{q}_{y}$ is the meridional gradient of zonal mean potential vorticity, $N^{2}$ is the buoyancy frequency, and $\beta$ is the variation of the Coriolis parameter with latitude. Since the basic state is inseparable for latitude and height, this equation is solved by using a QG model (Harnik and Lindzen, 2001), in which the wave numbers are diagnosed from the wave solution $\psi$, as $m^{2}=-\operatorname{Re}\left(\psi_{z z} / \psi\right)$ and $l^{2}=-\operatorname{Re}\left(\psi_{y y} / \psi\right)$. A reflecting surface for vertical propagation is the $m^{2}=0$ surface. Here, the coefficients of the wave Eq. (B4) are calculated using monthly mean zonal-mean zonal wind and temperature data.

\section{Appendix C: Statistical significance of anomalous values}

The statistical significance of the composite anomalies was evaluated using a Monte Carlo test similar to Lubis et al. (2016a) and Schreck et al. (2012). In this test, Null cases were identified using dates with the same months and days as the original composite, but from the other years. For example, if a DWC event in MERRA2 occurred on 17 February 1981, then its corresponding Null cases would be every 17 February from 1980 and from 1982 to 2013 . Null composites were calculated by randomly selecting the same number of dates from the Null cases as had been in the original composite. The Null hypothesis is that the difference between the composite anomaly and the broader population is zero. There are two ways to reject the Null hypothesis: (1) if the composite anomaly is greater than 975 of the 1000 random samples, and (2) if the composite anomaly is less than 975 of the 1000 random samples. That means that by random chance there is a 50 out of 1000 chance of rejecting the Null hypothesis, hence the $95 \%$ level. This significance test is advantageous since it accounts for the sample size and the possibility that variance may change with the time of year. 


\section{The Supplement related to this article is available online at doi:10.5194/acp-17-2437-2017-supplement.}

Competing interests. The authors declare that they have no conflict of interest.

Acknowledgements. This work is supported by the German-Israeli Foundation for Scientific Research and Development under grant GIF1151-83.8/2011. This work has also been partially performed within the Helmholtz University Young Investigators Group NATHAN funded by the Helmholtz Association through the Presidents Initiative and Networking Fund and the GEOMAR Helmholtz Centre for Ocean Research Kiel, Germany. Nili Harnik also acknowledges the support of a Rossby Visiting Fellowship from the International Meteorological Institute (IMI) of Stockholm University, Sweden. We also thank Mijeong Park for providing daily AURA-MLS ozone datasets and NASA's Global Modeling and Assimilation Office for providing the MERRA-1 and MERRA2 datasets. The authors are grateful to Susann Tegtmeier and the two anonymous reviewers whose insightful comments led to significant improvements of the paper. The model simulations were performed at the German Climate Computing Centre (Deutsches Klimarechenzentrum, DKRZ) in Hamburg, Germany.

The article processing charges for this open-access

publication were covered by a Research

Centre of the Helmholtz Association.

Edited by: T. J. Dunkerton

Reviewed by: four anonymous referees

\section{References}

Andrews, D. G., Holton, J. R., and Leovoy, C. B.: Middle Atmosphere Dynamics, in: vol. 40 of International Geophysics Series, Academic Press, Cambridge, Massachusetts, USA, 1987.

Austin, J. and Butchart, N.: Coupled chemistry-climate model simulations for the period 1980 to 2020: Ozone depletion and the start of ozone recovery, Q. J. Roy. Meteorol. Soc., 129, 32253249, doi:10.1256/qj.02.203, 2003.

Baldwin, M. P. and Dunkerton, T. J.: Stratospheric Harbingers of Anomalous Weather Regimes, Science, 294, 581-584, doi:10.1126/science.1063315, 2001

Bloom, S. C., Takacs, L. L., da Silva, A. M., and Ledvina, D.: Data Assimilation Using Incremental Analysis Updates, Mon. Weather Rev., 124, 1256-1271, doi:10.1175/15200493(1996)124<1256:DAUIAU>2.0.CO;2, 1996.

Bosilovich, M. G., Akella, S., Coy, L., Cullather, R., Draper, C., Gelaro, R., Kovach, R., Liu, Q., Molod, A., Norris, P., Wargan, K., Chao, W., Reichle, R., Takacs, L., Vikhliaev, Y., Bloom, S., Collow, A., Firth, S., Labows, G., Partyka, G., Pawson, S., Reale, O., Schubert, S. D., and Suarez, M.: MERRA-2: Initial Evaluation of the Climate. Technical Report Series on Global Modeling and Data Assimilation, Tech. Rep. NASA/TM-2015-104606, http://gmao.gsfc.nasa.gov/reanalysis/MERRA-2/docs/ (last access: 12 July 2016), 2015.
Brasseur, G. and Solomon, S.: Aeronomy of the Middle Atmosphere: Chemistry and Physics of the Stratosphere and Mesosphere, in: Atmospheric and Oceanographic Sciences Library, Springer Netherlands, 2005.

Charney, J. G. and Drazin, P. G.: Propagation of planetary-scale disturbances from the lower into the upper atmosphere, J. Geophys. Res., 66, 83-109, doi:10.1029/JZ066i001p00083, 1961.

Christiansen, B.: Downward propagation of zonal mean zonal wind anomalies from the stratosphere to the troposphere: Model and reanalysis, J. Geophys. Res.-Atmos., 106, 27307-27322, doi:10.1029/2000JD000214, 2001.

Dunn-Sigouin, E. and Shaw, T. A.: Comparing and contrasting extreme stratospheric events, including their coupling to the tropospheric circulation, J. Geophys. Res.-Atmos., 120, 1374-1390, doi:10.1002/2014JD022116, 2015.

Eyring, V., Cionni, I., Bodeker, G. E., Charlton-Perez, A. J., Kinnison, D. E., Scinocca, J. F., Waugh, D. W., Akiyoshi, H., Bekki, S., Chipperfield, M. P., Dameris, M., Dhomse, S., Frith, S. M., Garny, H., Gettelman, A., Kubin, A., Langematz, U., Mancini, E., Marchand, M., Nakamura, T., Oman, L. D., Pawson, S., Pitari, G., Plummer, D. A., Rozanov, E., Shepherd, T. G., Shibata, K., Tian, W., Braesicke, P., Hardiman, S. C., Lamarque, J. F., Morgenstern, O., Pyle, J. A., Smale, D., and Yamashita, Y.: Multimodel assessment of stratospheric ozone return dates and ozone recovery in CCMVal-2 models, Atmos. Chem. Phys., 10, 94519472, doi:10.5194/acp-10-9451-2010, 2010.

Fusco, A. C. and Salby, M. L.: Interannual Variations of Total Ozone and Their Relationship to Variations of Planetary Wave Activity, J. Climate, 12, 1619-1629, doi:10.1175/15200442(1999)012<1619:IVOTOA>2.0.CO;2, 1999.

Harnik, N.: Observed stratospheric downward reflection and its relation to upward pulses of wave activity, J. Geophys. Res.Atmos., 114, D08120, doi:10.1029/2008JD010493, 2009.

Harnik, N. and Heifetz, E.: Relating Overreflection and Wave Geometry to the Counterpropagating Rossby Wave Perspective: Toward a Deeper Mechanistic Understanding of Shear Instability, J. Atmos. Sci., 64, 2238-2261, doi:10.1175/JAS3944.1, 2007.

Harnik, N. and Lindzen, R. S.: The Effect of Reflecting Surfaces on the Vertical Structure and Variability of Stratospheric Planetary Waves, J. Atmos. Sci., 58, 2872-2894, doi:10.1175/15200469(2001)058<2872:TEORSO>2.0.CO;2, 2001.

Hommel, R., Eichmann, K.-U., Aschmann, J., Bramstedt, K., Weber, M., von Savigny, C., Richter, A., Rozanov, A., Wittrock, F., Khosrawi, F., Bauer, R., and Burrows, J. P.: Chemical ozone loss and ozone mini-hole event during the Arctic winter 2010/2011 as observed by SCIAMACHY and GOME-2, Atmos. Chem. Phys., 14, 3247-3276, doi:10.5194/acp-14-3247-2014, 2014.

$\mathrm{Hu}, \mathrm{J} ., \mathrm{Ren}, \mathrm{R}$., and Xu, H.: Occurrence of Winter Stratospheric Sudden Warming Events and the Seasonal Timing of Spring Stratospheric Final Warming, J. Atmos. Sci., 71, 2319-2334, doi:10.1175/JAS-D-13-0349.1, 2014.

Hurrell, J. W., Holland, M., Gent, P., Ghan, S., Kay, J. E., Kushner, P., Lamarque, J., Large, W., Lawrence, D., Lindsay, K., Lipscomb, W., Long, M., Mahowald, N., Marsh, D., Neale, R., Rasch, P., Vavrus, S., Vertenstein, M., Bader, D., Collins, W., Hack, J., Kiehl, J., and Marshall, S.: The Community Earth System Model: A Framework for Collaborative Research, B. Am. Meteorol. Soc., 94, 1339-1360, doi:10.1175/BAMS-D-1200121.1, 2013. 
Hurwitz, M. M., Newman, P. A., and Garfinkel, C. I.: The Arctic vortex in March 2011: a dynamical perspective, Atmos. Chem. Phys., 11, 11447-11453, doi:10.5194/acp-11-11447-2011, 2011.

Isaksen, I. S. A., Zerefos, C., Wang, W.-C., Balis, D., Eleftheratos, K., Rognerud, B., Stordal, F., Berntsen, T. K., LaCasce, J. H., Søvde, O. A., Olivié, D., Orsolini, Y. J., Zyrichidou, I., Prather, M., and Tuinder, O. N. E.: Attribution of the Arctic ozone column deficit in March 2011, Geophys. Res. Lett., 39, 124810, doi:10.1029/2012GL053876, 2012.

Kinnison, D. E., Brasseur, G. P., Walters, S., Garcia, R. R., Marsh, D. R., Sassi, F., Harvey, V. L., Randall, C. E., Emmons, L., Lamarque, J. F., Hess, P., Orlando, J. J., Tie, X. X., Randel, W., Pan, L. L., Gettelman, A., Granier, C., Diehl, T., Niemeier, U., and Simmons, A. J.: Sensitivity of chemical tracers to meteorological parameters in the MOZART-3 chemical transport model, J. Geophys. Res.-Atmos., 112, D20302, doi:10.1029/2006JD007879, 2007.

Kuroda, Y. and Kodera, K.: Role of planetary waves in the stratosphere-troposphere coupled variability in the northern hemisphere winter, Geophys. Res. Lett., 26, 2375-2378, doi:10.1029/1999GL900507, 1999.

Lean, J., Rottman, G., Harder, J., and Kopp, G.: SORCE Contributions to New Understanding of Global Change and Solar Variability, Springer, New York, 27-53, doi:10.1007/0-387-376259_3, 2005.

Limpasuvan, V., Thompson, D. W., and Hartmann, D. L.: The Life Cycle of the Northern Hemisphere Sudden Stratospheric Warmings, J. Climate, 17, 2584-2596, doi:10.1175/15200442(2004)017<2584:TLCOTN>2.0.CO;2, 2004.

Lubis, S. W., Matthes, K., Omrani, N.-E., Harnik, N., and Wahl, S.: Influence of the Quasi-Biennial Oscillation and Sea Surface Temperature Variability on Downward Wave Coupling in the Northern Hemisphere, J. Atmos. Sci., 73, 1943-1965, doi:10.1175/JAS-D-15-0072.1, 2016a.

Lubis, S. W., Omrani, N.-E., Matthes, K., and Wahl, S.: Impact of the Antarctic Ozone Hole on the Vertical Coupling of the Stratosphere-Mesosphere-Lower Thermosphere System, J. Atmos. Sci., 73, 2509-2528, doi:10.1175/JAS-D-15-0189.1, 2016b.

Manney, G. L., Santee, M. L., Rex, M., Livesey, N. J., Pitts, M. C., Veefkind, P., Nash, E. R., Wohltmann, I., Lehmann, R., Froidevaux, L., Poole, L. R., Schoeberl, M. R., Haffner, D. P., Davies, J., Dorokhov, V., Gernandt, H., Johnson, B., Kivi, R., Kyro, E., Larsen, N., Levelt, P. F., Makshtas, A., McElroy, C., Nakajima, H., Parrondo, M. C., Tarasick, D. W., von der Gathen, P., Walker, K. A., and Zinoviev, N. S.: Unprecedented Arctic ozone loss in 2011, Nature, 478, 469-475, doi:10.1038/nature10556, 2011.

Marsh, D. R., Mills, M. J., Kinnison, D. E., Lamarque, J.-F., Calvo, N., and Polvani, L. M.: Climate Change from 1850 to 2005 Simulated in CESM1 (WACCM), J. Climate, 26, 7372-7391, doi:10.1175/JCLI-D-12-00558.1, 2013.

Matthes, K., Marsh, D. R., Garcia, R. R., Kinnison, D. E., Sassi, F., and Walters, S.: Role of the QBO in modulating the influence of the 11 year solar cycle on the atmosphere using constant forcings, J. Geophys. Res.-Atmos., 115, D18110, doi:10.1029/2009JD013020, 2010.

McIntyre, M. E. and Palmer, T. N.: Breaking planetary waves in the stratosphere, Nature, 305, 593-600, doi:10.1038/305593a0, 1983.
Newman, P. A., Nash, E. R., and Rosenfield, J. E.: What controls the temperature of the Arctic stratosphere during the spring?, J. Geophys. Res.-Atmos., 106, 19999-20010, doi:10.1029/2000JD000061, 2001.

Perlwitz, J. and Harnik, N.: Observational Evidence of a Stratospheric Influence on the Troposphere by Planetary Wave Reflection, J. Climate, 16, 3011-3026, doi:10.1175/15200442(2003)016<3011:OEOASI>2.0.CO;2, 2003.

Plumb, R. A.: Stratospheric Transport, J. Meteorol. Soc. Jpn. Ser. II, 80, 793-809, doi:10.2151/jmsj.80.793, 2002.

Plumb, R. A. and Semeniuk, K.: Downward migration of extratropical zonal wind anomalies, J. Geophys. Res.-Atmos., 108, 4223 , doi:10.1029/2002JD002773, 2003.

Polvani, L. M. and Waugh, D. W.: Upward Wave Activity Flux as a Precursor to Extreme Stratospheric Events and Subsequent Anomalous Surface Weather Regimes, J. Climate, 17, 3548-3554, doi:10.1175/15200442(2004)017<3548:UWAFAA>2.0.CO;2, 2004.

Randel, W. J.: Global Variations of Zonal Mean Ozone during Stratospheric Warming Events, J. Atmos. Sci., 50, 3308-3321, doi:10.1175/1520-0469(1993)050<3308:GVOZMO>2.0.CO;2, 1993.

Randel, W. J., WU, F., and Stolarski, R.: Changes in Column Ozone Correlated with the Stratospheric EP Flux, J. Meteorol. Soc. Jpn. Ser. II, 80, 849-862, doi:10.2151/jmsj.80.849, 2002.

Rienecker, M. M., Suarez, M. J., Gelaro, R., Todling, R., Bacmeister, J., Liu, E., Bosilovich, M. G., Schubert, S. D., Takacs, L., Kim, G., Bloom, S., Chen, J., Collins, D., Conaty, A., da Silva, A., Gu, W., Joiner, J., Koster, R. D., Lucchesi, R., Molod, A., Owens, T., Pawson, S., Pegion, P., Redder, C. R., Reichle, R., Robertson, F. R., Ruddick, A. G., Sienkiewicz, M., and Woollen, J.: MERRA: NASA's Modern-Era Retrospective Analysis for Research and Applications, J. Climate, 24, 3624-3648, doi:10.1175/JCLI-D-11-00015.1, 2011.

Rose, K. and Brasseur, G.: Atmospheric Ozone: Proceedings of the Quadrennial Ozone Symposium held in Halkidiki, Greece 3-7 September 1984, in: chap. Ozone During Sudden Stratospheric Warming: A Three-Dimensional Simulation, Springer Netherlands, Dordrecht, 28-32, doi:10.1007/978-94-009-53130_6, 1985.

Schreck, C. J., Shi, L., Kossin, J. P., and Bates, J. J.: Identifying the MJO, Equatorial Waves, and Their Impacts Using 32 Years of HIRS Upper-Tropospheric Water Vapor, J. Climate, 26, 14181431, doi:10.1175/JCLI-D-12-00034.1, 2012.

Shaw, T. A. and Perlwitz, J.: The Life Cycle of Northern Hemisphere Downward Wave Coupling between the Stratosphere and Troposphere, J. Climate, 26, 1745-1763, doi:10.1175/JCLI-D12-00251.1, 2013.

Shaw, T. A. and Perlwitz, J.: On the Control of the Residual Circulation and Stratospheric Temperatures in the Arctic by Planetary Wave Coupling, J. Atmos. Sci., 71, 195-206, doi:10.1175/JASD-13-0138.1, 2014.

Shaw, T. A., Perlwitz, J., and Harnik, N.: Downward Wave Coupling between the Stratosphere and Troposphere: The Importance of Meridional Wave Guiding and Comparison with Zonal-Mean Coupling, J. Climate, 23, 6365-6381, doi:10.1175/2010JCLI3804.1, 2010.

Shaw, T. A., Perlwitz, J., and Weiner, O.: Troposphere-stratosphere coupling: Links to North Atlantic weather and climate, including 
their representation in CMIP5 models, J. Geophys. Res.-Atmos., 119, 5864-5880, doi:10.1002/2013JD021191, 2014.

Solomon, S.: Stratospheric ozone depletion: A review of concepts and history, Rev. Geophys., 37, 275-316, doi:10.1029/1999RG900008, 1999.

SPARC CCMVal: SPARC report on the evaluation of chemistryclimate models, SPARC-Report No. 5, WCRP-132, WMO/TDNo. 1526, SPARC, Zurich, Switzerland, available at: http://www. sparc-climate.org/publications/sparc-reports/sparc-report-no5/ (last access: February 2017), 2010.

Tegtmeier, S., Rex, M., Wohltmann, I., and Krüger, K.: Relative importance of dynamical and chemical contributions to Arctic wintertime ozone, Geophys. Res. Lett., 35, 117801, doi:10.1029/2008GL034250, 2008.
Waters, J. W., Froidevaux, L., Harwood, R. S., Jarnot, R. F., Pickett, H. M., Read, W. G., Siegel, P. H., Cofield, R. E., Filipiak, M. J., Flower, D. A., Holden, J. R., Lau, G. K., Livesey, N. J., Manney, G. L., Pumphrey, H. C., Santee, M. L., Wu, D. L., Cuddy, D. T., Lay, R. R., Loo, M. S., Perun, V. S., Schwartz, M. J., Stek, P. C., Thurstans, R. P., Boyles, M. A., Chandra, K. M., Chavez, M. C., Chen, G.-S., Chudasama, B. V., Dodge, R., Fuller, R. A., Girard, M. A., Jiang, J. H., Jiang, Y., Knosp, B. W., LaBelle, R. C., Lam, J. C., Lee, K. A., Miller, D., Oswald, J. E., Patel, N. C., Pukala, D. M., Quintero, O., Scaff, D. M., Snyder, W. V., Tope, M. C., Wagner, P. A., and Walch, M. J.: The Earth observing system microwave limb sounder (EOS MLS) on the aura Satellite, IEEE T. Geosci. Remote, 44, 1075-1092, doi:10.1109/TGRS.2006.873771, 2006.

Weber, M., Dhomse, S., Wittrock, F., Richter, A., Sinnhuber, B.M., and Burrows, J. P.: Dynamical control of NH and SH winter/spring total ozone from GOME observations in 1995-2002, Geophys. Res. Lett., 30, 1583, doi:10.1029/2002GL016799, 2003. 